\title{
Multi-decadal trends and variability in temperature and salinity in the Mid-Atlantic Bight, Georges Bank, and Gulf of Maine
}

\author{
Elizabeth J. Wallace \\ Lev B. Looney \\ Donglai Gong \\ Virginia Institute of Marine Science
}

Follow this and additional works at: https://scholarworks.wm.edu/vimsarticles

Part of the Oceanography Commons

\section{Recommended Citation}

Wallace, Elizabeth J.; Looney, Lev B.; and Gong, Donglai, "Multi-decadal trends and variability in temperature and salinity in the Mid-Atlantic Bight, Georges Bank, and Gulf of Maine" (2018). VIMS Articles. 1860.

https://scholarworks.wm.edu/vimsarticles/1860

This Article is brought to you for free and open access by the Virginia Institute of Marine Science at W\&M ScholarWorks. It has been accepted for inclusion in VIMS Articles by an authorized administrator of W\&M ScholarWorks. For more information, please contact scholarworks@wm.edu. 


\title{
Multi-decadal trends and variability in temperature and salinity in the Mid-Atlantic Bight, Georges Bank, and Gulf of Maine
}

\author{
by Elizabeth J. Wallace' ${ }^{1}$, Lev B. Looney ${ }^{2}$ and Donglai Gong ${ }^{3,4}$
}

\begin{abstract}
Increasing attention is being placed on the regional impact of climate change. This study focuses on the decadal scale variabilities of temperature and salinity in the Mid-Atlantic Bight (MAB), Georges Bank (GB), and Gulf of Maine (GOM) from 1977 to 2016 using hydrographic survey data from the National Oceanic and Atmospheric Administration (NOAA) Northeast Fisheries Science Center. The $\mathrm{MAB}$ (as defined by the shelf regions from Cape Hatteras to Cape Cod) experienced warming rates of $0.57^{\circ} \mathrm{C}$ per decade during the Winter/Spring season (Jan-Apr) and $0.47^{\circ} \mathrm{C}$ per decade during the Fall/Winter season (Sep-Dec). The GOM and GB, on the other hand, warmed at approximately half the rate of the MAB over the same time span (1977-2016). We found that rates of warming vary on decadal time scales. From 1977 to 1999 , significant temperature increases $\left(>0.6{ }^{\circ} \mathrm{C} /\right.$ decade $)$ were found in the southern regions of the MAB during the Winter/Spring season. During the same period, significant freshening (stronger than -0.2 decade) was found in GB and the northern regions of the MAB during the Winter/Spring and Summer seasons. From 1999 to 2016, on the other hand, we found no significant trends in temperature and few significant trends in salinity with the exceptions of some northern MAB regions showing significant salting. Interannual variability in shelf salinity can in part be attributed to river discharge variability in the Hudson River and Chesapeake Bay. However, decadal scale change in shelf salinity cannot be attributed to changes in river discharge as there were no significant decadal scale changes in river outflow. Variability in along-shelf freshwater transport and saline intrusions from offshore were the likely drivers of long-term changes in MAB shelf-salinity.

Keywords: Middle Atlantic Bight, Georges Bank, continental shelf, decadal variability, shelf salinity, hydrography
\end{abstract}

\section{Introduction}

The Mid-Atlantic Bight (MAB), Georges Bank (GB), and Gulf of Maine (GOM) are major oceanographic domains off the U.S. East Coast that stretch from Cape Hatteras,

1. Department of Geology and Geophysics, Woods Hole Oceanographic Institution, Woods Hole, MA USA 02543.

2. School of the Earth, Ocean, and Environment, University of South Carolina, Columbia, SC USA 29208.

3. Department of Physical Sciences, Virginia Institute of Marine Science, College of William and Mary, Gloucester, VA USA 23062.

4. Corresponding author e-mail: gong@vims.edu

(C) 2018 Elizabeth J. Wallace, Lev B. Looney and Donglai Gong. 
North Carolina northward to Nova Scotia, Canada. They encompass estuaries, continental shelves, shelf-breaks, slopes, shoals, and channels. The MAB stretches $850 \mathrm{~km}$ along the continental shelf with a width of approximately $100 \mathrm{~km}$ in the northern MAB and $30 \mathrm{~km}$ at the southern end. The total area of the MAB is over $110,000 \mathrm{~km}^{2}$. On the inshore side, the MAB is bounded by a number of large bays and estuaries such as the Hudson, Delaware, and Chesapeake Bay estuaries. On the offshore side, it is bounded by the Slope Sea and the Gulf Stream (Mountain 2003). The maximum shelf depth decreases from about $100 \mathrm{~m}$ in the northern MAB to less than $40 \mathrm{~m}$ in the southern MAB (Lentz 2008). In general, the flow in the MAB is along-shelf from the northeast to the southwest.

Just north of the MAB lies Georges Bank. GB is a relatively shallow offshore region with depths between 20 and 100 meters and an area of approximately $30,000 \mathrm{~km}^{2}$. GB is surrounded by the GOM to the north and the Atlantic Ocean to the south. GB is separated from the Scotian Shelf to the northeast by the Northeast Channel and from the MAB to the west by the Great South Channel. Water in the GB is primarily fed by inflow from the GOM and upwelling along its margins. Circulation over GB is complex and largely tidally driven. It is also a highly biologically productive region of the ocean known for its fisheries. The GOM is a large gulf to the north of both the MAB and GB with a total area of approximately $90,000 \mathrm{~km}^{2}$ and depth ranging between 100 and $240 \mathrm{~m}$ (Thompson 2010). The GOM is fed by Scotian shelf inflow and a number of smaller estuaries such as the Penobscot, Kennebec, Androscoggin, Saco, and Saint John. The circulation in the GOM is generally counterclockwise (Bigelow 1927).

On average, the shelf water shoreward of the shelf break is cooler and fresher than the slope water seaward of the shelf. These differing water masses are separated by a sharp transition region known as the shelf-break front (Chapman 1986). The coastal current that flows along the MAB, GB, and GOM is part of an extended coastal circulation system that transports water from the subarctic seas to the temperate shelves (Chapman and Beardsley 1989). Fleming (2016) characterized the seasonal variability in the MAB, GB, and GOM regions and the drivers of the seasonal variability in detail. In addition, changes in the physical and biological state of the MAB have been observed on interannual and decadal time scales (Mountain 2003; Schofield et al. 2008; Forsyth et al. 2015).

Observed changes in the MAB and surrounding regions coincide with recent changes in the global climate. The latest assessment by the Intergovernmental Panel on Climate Change (IPCC) predicted a global rise in temperature of $3.2^{\circ} \mathrm{C}$ to $7.2{ }^{\circ} \mathrm{C}$ and an average sea level rise of 17 to $58 \mathrm{~cm}$ by the end of the century (Appiott et al. 2011). Regional sea level rise along the U.S. Mid-Atlantic coast is expected to be significantly higher (Boon 2012; Ezer et al. 2013). In addition, over the past three decades, there has been amplified warming in the Arctic region, resulting in extensive melting of sea ice in the summer (Belchansky et al. 2004; Markus et al. 2009; Korhonen et al. 2013). The melting sea ice carried southward into the North Atlantic and the subpolar shelves can result in an influx of cold freshwater, which could alter ocean circulation as well as regional heat and freshwater budgets (Fogarty et al. 2007). Indeed, recent studies contain evidence for a weakening of the Atlantic Meridional 
Overturning Circulation (AMOC), the North Atlantic Ocean main heat conveyor belt, over the past 150 years (Thornalley et al. 2018; Caesar et al. 2018).

The estuaries, continental shelves, and shelf break canyons in the MAB, GB, and GOM are home to a rich diversity of aquatic life, and the coastal ocean functions as a migratory pathway for many marine species (Fogarty et al. 2007). Long-term changes in the physical oceanographic state of the MAB, GB, and GOM will likely impact the marine ecosystems along the U.S. East Coast. Significant deviations from the seasonal patterns of temperature and stratification variations can affect primary and secondary productivity and place increased stress on many species of fish and the associated commercial fisheries (Mountain and Taylor 1998). Ergo, it is paramount for us to track and understand long-term changes in temperature and salinity and their physical drivers in the MAB.

Recent studies have already begun to show the impacts of climate change on the MAB. Forsyth et al. (2015) analyzed the relationship between water temperature on the continental shelf off New Jersey and coastal sea levels and found that from 1977 to 2013 the depthaveraged shelf temperature increased at $0.26 \pm 0.01^{\circ} \mathrm{C}$ per decade with accelerated warming in the last decade. Mountain's (2003) study characterizing decadal scale changes in the temperature, salinity, and shelf water volume of the MAB from 1977 to 1999 reported that the shelf water of the MAB in the 1990s was "approximately $1{ }^{\circ} \mathrm{C}$ warmer, $0.25 \mathrm{PSU}$ fresher, and $1,000 \mathrm{~km}^{3}$ more abundant than during the 1977-1987 period". Mountain (2003) also found salinity variability on GB from 1977 to 1999 similar to that found on the MAB. In this study, we expanded and improved key parts of Mountain's analysis to assess long term and more recent changes in the MAB, GB, and GOM in a statistically robust manner. We characterized the seasonal to decadal scale changes in the temperature and salinity of both the shelf water only portion and the all water masses included portion across a 40-year span (1977-2016) and explored possible physical drivers of the observed changes.

The organization of the paper is as follows. Section 2 provides background on the circulation along the U.S. East Coast (Section 2a) and the temperature and salinity characteristics of the MAB and GB (Section 2b). Section 3 provides a description of the data-set used in this study and the data analysis methodology. Section 4 characterizes the seasonal cycle (Section 4a), general trends (Section $4 \mathrm{~b}$ ), decadal variability of temperature and salinity change (Section 4c), and decadal variability of temperature and salinity profiles (Section 4d) for each region analyzed. Section 5 discusses the results obtained in this study in terms of general trends (Section 5a) and decadal variability (Section 5b). Finally, Section 6 offers a summary of the main findings of the study.

\section{Background}

\section{a. Overall circulation across US Northeast coast}

Along-shelf transport in the MAB and GB is part of a large-scale coastal current that extends from the west coast of Greenland to Cape Hatteras (Fairbanks 1982). According to analyses of geochemical tracers, the upstream source of the MAB shelf water is located 
in the Northern Labrador Sea (Fairbanks 1982; Chapman and Beardsley 1989). This water flows southward around Newfoundland and along the Scotian shelf before entering the GOM (Smith 1983). It is in the GOM that the MAB shelf water is formed as a water mass (Mountain and Manning 1994). The GOM has two significant inflows: fresh cool water from the Scotian shelf entering at the surface around Cape Sable and the deep flow of warmer, more saline slope water through the Northeast Channel (Mountain and Manning 1994). These distinct inflows are then mixed and modified in the presence of local atmospheric conditions, runoff, and precipitation (Manning 1991). From the western GOM, this product exits near surface into the clockwise circulation around GB before entering the MAB near Nantucket Island. While most of the Scotian shelf water enters the GOM, about $30 \%$ crosses over directly into the eastern GB through the Northeast Channel (Chapman et al. 1986). The volume transport of shelf water into the MAB is approximately $0.4 \mathrm{~Sv}$ (Beardsley et al. 1985). Once in the MAB, the mean circulation is observed to be directed equatorward from northeast to southwest with an average speed of $3-10 \mathrm{~cm} \mathrm{~s}^{-1}$ (Beardsley and Boicourt 1981; Lentz 2008). However, the flow on the shelf is affected by wind forcing events and water column stratification on event to seasonal time scales (Gong et al. 2010). Cape Hatteras marks the points where the mean southward along-shelf flow ends and where the flow exits the MAB and feeds into the northward flowing Gulf Stream (Walsh et al. 1988).

\section{b. Temperature and salinity distributions in the $M A B$ and $G B$}

The physical properties of the shelf water are affected by its upstream sources as well as local transformation processes. Throughout the MAB and GB, the shelf water properties undergo changes on various spatial and temporal scales due to variations in seasonal temperature, precipitation, river runoff, wind mixing/advection, and intrusions of offshore oceanic water (Lentz 2008; Lentz 2010; Gong 2010; Fleming 2016). The northern MAB is most heavily influenced by the influx of cold and fresher water from the sub-Arctic shelves, whereas the southern MAB is influenced by the cross-shelf exchanges of warm and saline water from the Gulf Stream (Fogarty et al. 2007). In general, mean annual depth-averaged temperatures increase southward from approximately $8.5^{\circ} \mathrm{C}$ in the $\mathrm{GB}$ to $12{ }^{\circ} \mathrm{C}$ near the Chesapeake Bay. The along-shelf temperature increases from north to south can mainly be attributed to the along-shelf atmosphere-ocean heat flux gradient. At the same location, the seasonal temperature range can vary from $20^{\circ} \mathrm{C}$ near the surface in the summer to $5{ }^{\circ} \mathrm{C}$ in the winter (Beardsley et al. 1985; Beardsley and Boicourt 1981; Lentz 2010). The large seasonal temperature variations are caused by surface heat flux with solar heating of the oceans in the summer and latent and sensible heat loss in the winter (Lentz 2010; Fleming 2016).

The average shelf salinity increases from about 32.5 over GB to 33.5 near the Chesapeake Bay. Salinity, unlike temperature, does not follow a clear seasonal cycle, instead it shows significant interannual variability. Manning (1991) attributed this interannual variation predominantly to year to year changes in precipitation and river discharge. The freshest shelf 
water is found at the mouths of major estuaries. The river water is then mixed with the shelf water and advected down-shelf or cross-shelf. Generally, water near the coast starts with a salinity of 32 and increases to a salinity of about 34 at the shelf-break (Chapman and Beardsley 1989; Lentz 2008; Manning 1991).

There are numerous studies about temperature and salinity variability on the U.S. Northeast coast. Mountain and Taylor (1998) showed that variations in salinity and temperature (surface and bottom) are coherent over the entire shelf region from the Chesapeake Bay to the GOM. Lentz (2010) looked at the surface fluxes of heat and freshwater in the MAB and found that depth-averaged temperature and salinity along-isobaths increased from north to south. An offshore source of salinity is needed to balance the shelf salinity budget. Smith et al. (2001) observed a lower salinity in the GOM during the 1990s that he attributed to a larger inflow of Scotian slope water (Smith et al. 2001). In addition, Mountain (1991) found that the interannual changes in shelf water volume in the MAB are correlated with the flow through the GOM system (Mountain 1991).

Observational data covering the whole MAB and GB spanning several decades are valuable for characterizing the effects of both local and remote influences in different parts of the system. Mountain's (2003) study extensively characterized the interannual variability in temperature, salinity, and shelf water volume in the MAB up to 1999. Using the same dataset for the earlier periods and additional data from more recent times, we conducted a statistically robust and in-depth investigation of decadal scale variabilities in the MAB, GB, and GOM from 1977 until 2016. Given the potential changes that have occurred over the last decade and a half, this analysis is important for understanding and preparing for future changes.

\section{Data and Methods}

\section{a. Data analysis}

The analysis of temperature and salinity was conducted using quality-controlled publicly available hydrographic survey data from National Oceanic and Atmospheric Administration (NOAA)'s Northeast Fisheries Science Center (NEFSC; ftp://ftp.nefsc.noaa.gov/pub/hydro; Fratantoni et al. 2013). We used available full year data for the MAB, GB, and GOM from 1977 to 2016. As noted by Mountain (2003), from a data collection perspective, the hydrographic dataset can be separated into two periods. The first part of the data was collected during the Marine Resources Monitoring, Assessment, and Prediction (MARMAP) program of the NEFSC from 1977 to 1987, which surveyed the shelf from Cape Hatteras to GB and the GOM (Sherman 1980). The MARMAP observations were made at 49 standard stations during each survey, although not every station was occupied during each survey. The surveys measured water properties as well as the distribution of nutrients and plankton. Most of the measurements were taken by water sampling bottles with reversing thermometers at up to 15 standard depths (Meise-Munns et al. 1990). For the last year (1987) in the MARMAP period, an electronic conductivity-temperature-depth (CTD) instrument was 
utilized (Mountain 2003). The second part of the hydrographic data extends from 1991 to 2016, and it consists of routine observations made by the NEFSC utilizing an electronic CTD profiling device (Fratantoni et al. 2013). During each survey, the data were collected at 70 randomly selected stations across the MAB. Unlike the earlier MARMAP dataset, the station locations varied from year to year and from season to season.

In order to study the interannual and decadal variations in the water mass properties for each season, the data were divided into three seasons for each year. We used similar seasonal period definitions as Mountain (2003) but modified the periods slightly so that each period contained four full months. This change allows us to do a seasonal averaging bias correction based on the monthly climatological data. The Winter/Spring season extends from the beginning of January to the end of April (Calendar days 1-120), the Summer season was from the beginning of May to the end of August (Calendar days 121-243), and Fall/Winter season was from September to the end of December (Calendar days 244-365). Unfortunately, some of the regions lacked data from 1987 to 1991 because of gaps in survey sampling during that time period.

To analyze the spatial variation in water column properties, the shelf off the US East Coast is divided into 8 distinct regions. Moving from north to south, the eight regions are GOM, GB, Eastern New England (ENE), Southern New England (SNE), New York Bight 1 (NYB1), New York Bight 2 (NYB2), Southern Shelf 1 (SS1), and Southern Shelf 2 (SS2). In addition, we defined the MAB as encompassing the five southern-most regions (similar to the regions defined by Mountain 2003 but modified to better encompass the inner shelf domain). These regions are all depicted in Figure 1. The volume for each region was calculated using the General Bathymetric Chart of the Oceans (GEBCO) 30 arc-second resolution gridded bathymetry (Weatherall et al. 2015). Within each study region, we used only data with bathymetric depths between 6 and 1,000 meters for the calculations. This depth range encompasses most of the continental shelves, the shelf break, upper continental slope, and submarine canyons, excluding the very shallow nearshore and coastal estuarine regions. The area of each bathymetric grid box within GEBCO is calculated by

$$
A=\left(\triangle L A T * \frac{1852 m}{1 \operatorname{arcmin} \text { of } L A T}\right) *\left(\Delta L O N * \frac{\cos (L A T) * 1852 m}{1 \operatorname{arcmin} \text { of } L O N}\right)
$$

where $\triangle L A T$ and $\triangle L O N$ are the resolution of the GEBCO grid in arc-minutes. In our case, both values are 0.5 arc-minutes. Both terms are converted from arc minutes to meters by assuming one arc-minute of latitude or longitude at the equator as one nautical mile, or $1852 \mathrm{~m}$ (Göbel et al. 2006). The cosine of latitude term modifies the conversion based on the spherical shape of the earth. Thus, the area of a GEBCO grid box ranges from $0.64 \mathrm{~km}^{2}$ to $0.7 \mathrm{~km}^{2}$ depending on the latitude of the grid box. Multiplying the area of each GEBCO grid by the depth at each grid gives the grid box's volume.

For each of the above-defined regions with CTD station coverage, the volume-weighted temperature $(\mathrm{T})$ and salinity $(\mathrm{S})$ were determined for each season of every year according to the following procedure. First, each CTD temperature and salinity profile was linearly 


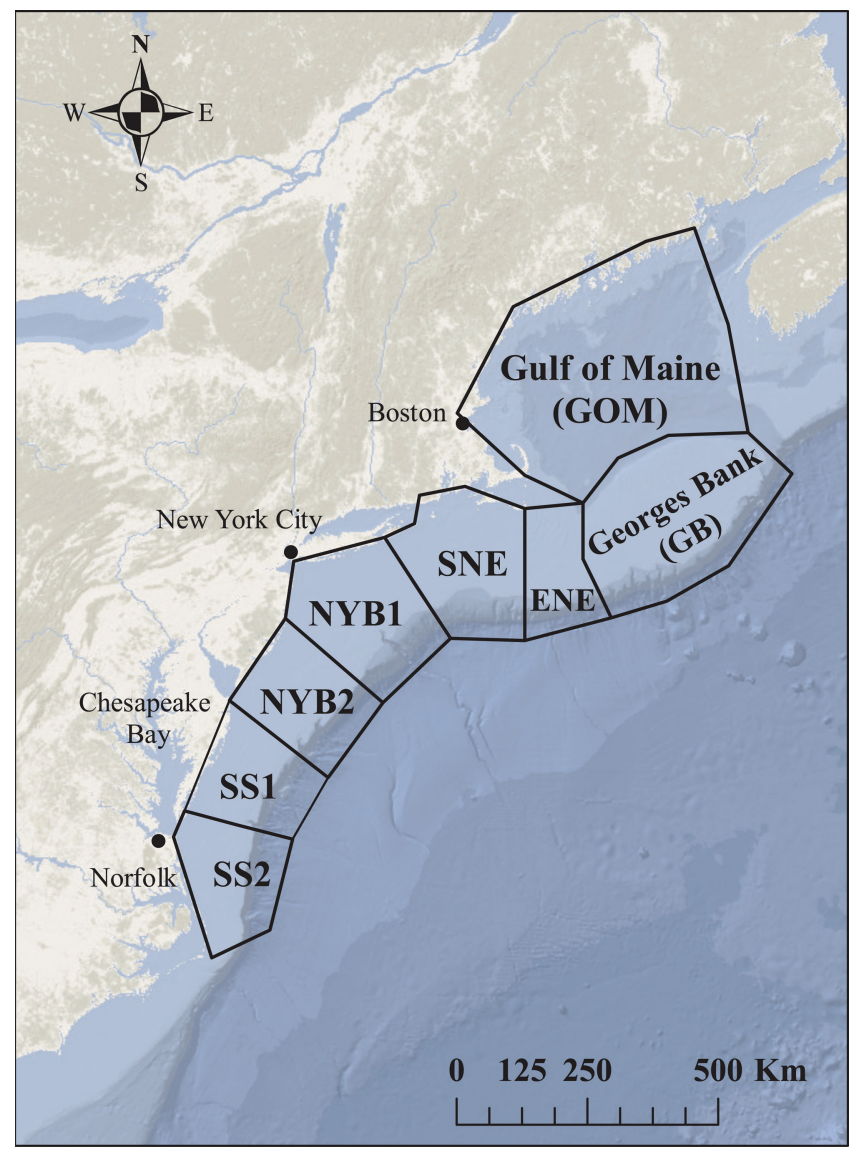

Figure 1. The Mid-Atlantic Bight (MAB), Georges Bank (GB), and Gulf of Maine (GOM). Regions used in this study are demarcated.

interpolated onto a 1-meter vertical resolution grid at each CTD station. If the bathymetry depth at the CTD station was deeper than the deepest measurement of the CTD profile, then the deepest profile values taken at the CTD station were extended to the depths of the bathymetry (Figure $2 b$ ). This vertical extension of the temperature and salinity profiles is reasonable based on the observation that the water properties in the bottom boundary layer $(\sim 10 \mathrm{~m})$ remain essentially constant with depth (Pickart 2000$)$. The distance between the deepest measurement of each CTD cast and the depth of the bottom is typically $5 \mathrm{~m}$ or less.

Next, each profile is depth-averaged to obtain the depth-averaged $\mathrm{T}$ and $\mathrm{S}$ values for each CTD station. The depth-averaged $\mathrm{T}$ and $\mathrm{S}$ values are then horizontally interpolated onto the GEBCO gridded bathymetry using a modified Shepard inverse distance weighting (IDW) method (Shepard 1968) by utilizing the nearest CTD stations within a user-specified search radius. The weights are calculated using the formula 

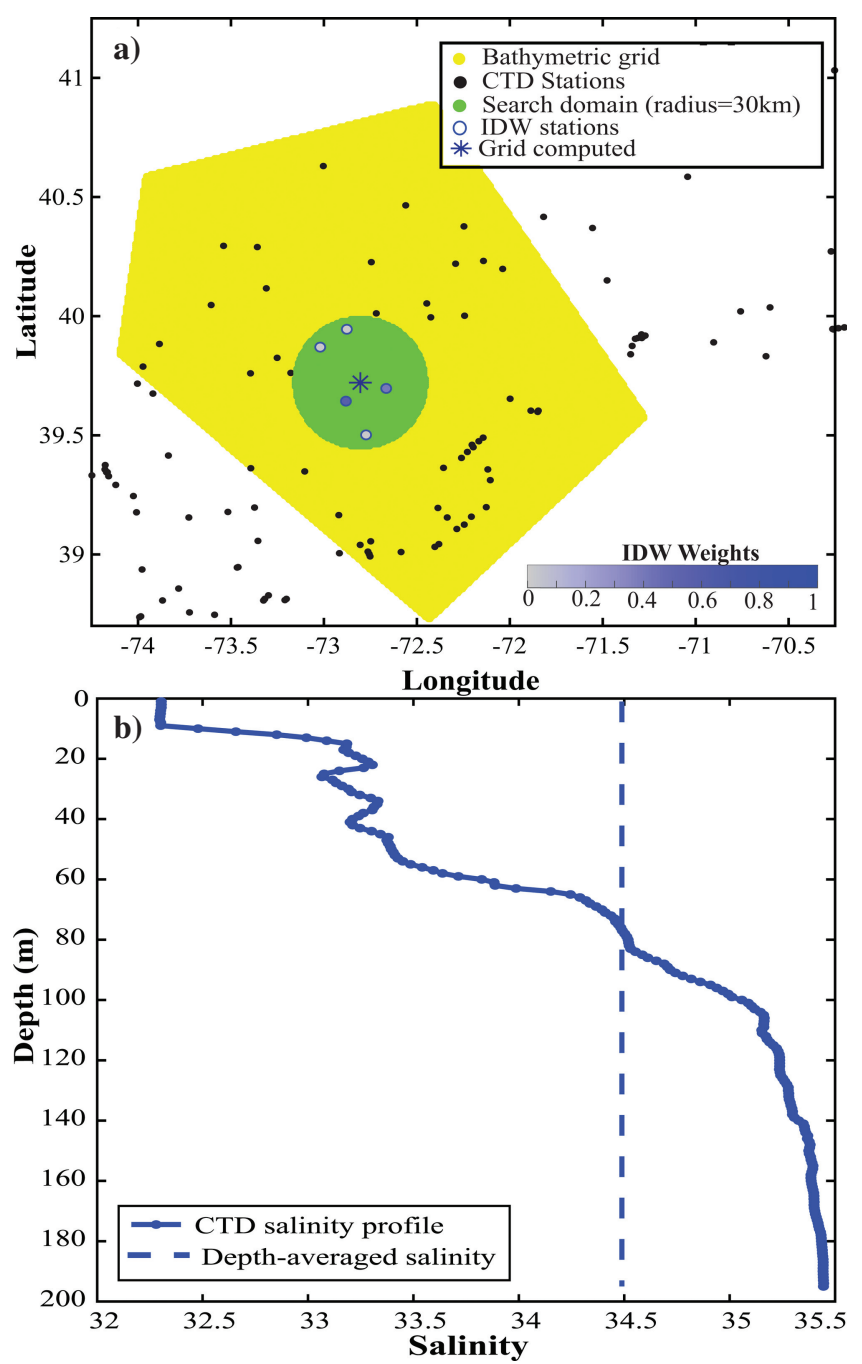

Figure 2. (a) Schematic of the inverse distance weighting scheme for New York Bight 1 (NYB1) for the Summer season in 2009. The bathymetric grid points are shown in yellow and the conductivitytemperature-depth (CTD) stations in that season and year shown in black. An example user defined radius (green) around a specific bathymetric grid (blue star) is shown with the encompassed IDW stations and their respective weights. (b) An example of a salinity profile. The shelf water $(\mathrm{S}<34)$ portion is labeled and the deepest data point is extrapolated to the bottom depth. 


$$
w_{k}(x)=\left(\frac{\max \left(0, R-d\left(x, x_{k}\right)\right)}{R d\left(x, x_{k}\right)}\right)^{P}
$$

where $w_{k}$ is the weight of the $\mathrm{k}^{\text {th }}$ CTD station profile, $x$ is the location of each GEBCO bathymetric grid box, $x_{k}$ is the location of the $\mathrm{k}^{\text {th }}$ CTD station, $d$ is the distance function, $R$ is the user-specified search radius for the nearest CTD stations (Fig. 2a), and $P$ is the power parameter. For this study, we chose an $R$ of $30 \mathrm{~km}$ and $P$ of 2 . We chose these values to be a reasonable compromise between spatial resolution, data availability, and near field versus far field influence. Through a sensitivity analysis, we found that the estimates of regionally-averaged $\mathrm{T}$ and $\mathrm{S}$ (using the method described in the next paragraph) were relatively insensitive to the values of $R$ and $P$ for the range of values we tested (20 km < $R<40 \mathrm{~km}$ and $1<P<4$; see Fig. A1). The nearest neighbor search for the IDW calculation was done on a k-d tree partitioning of the CTD station locations (Bentley 1975). The spatially-weighted average of the depth-averaged temperature and salinity are then calculated for each GEBCO bathymetric grid box.

Once the temperature, salinity, and volume for each GEBCO bathymetric grid box are calculated, the volume-weighted temperature and salinity for each of the regions are calculated using the formula

$$
[T, S]_{j}=\frac{\sum_{i}[T, S]_{i} * V_{i}}{V_{j}}
$$

where $[T, S]_{j}$ is the volume weighted temperature or salinity for the $j^{\text {th }}$ region, $[T, S]_{i}$ are the temperature or salinity values at GEBCO bathymetric grid box $i, V_{i}$ is the unit volume at each GEBCO grid box, $V_{j}$ is the total volume of region $j$, and $i$ is the index number of the GEBCO grid box within region $j$. Across all seasons, the number of stations contributing to the calculations for a particular region ranges from 5 to 90 , with an average of approximately 27 .

In order to identify whether the variability on the MAB shelf was a result of change in the shelf water properties, change in the slope water properties, or simply changes in the relative volumes of the two water masses, the average temperature and salinity of the shelf water only component for each region and each season were determined for each year. Shelf water was defined as the volume of water with a salinity less than 34 (Manning 1991; Mountain 2003). In general, most of the water shoreward of the shelf has a salinity range between 32.25 and 33.75 whereas the minimum salinity in the slope water seaward of the shelf is usually between 34 and 35 (Manning 1991). Based on this shelf water definition, we classified shelf water at a given GEBCO grid point in a depth-averaged sense.

The regionally averaged temperature and salinity as defined above were computed for each region and each season of each year. Using these yearly values and the volumes of each region, a volume-weighted average temperature and salinity for the entire MAB, GB, 
All water masses (1977-2016)
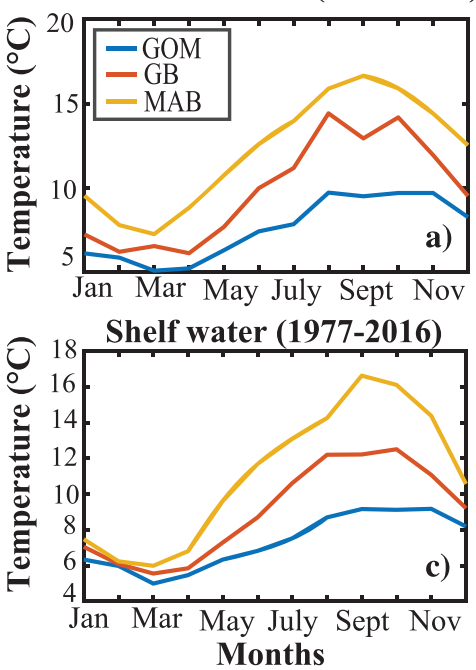

All water masses (1977-2016)
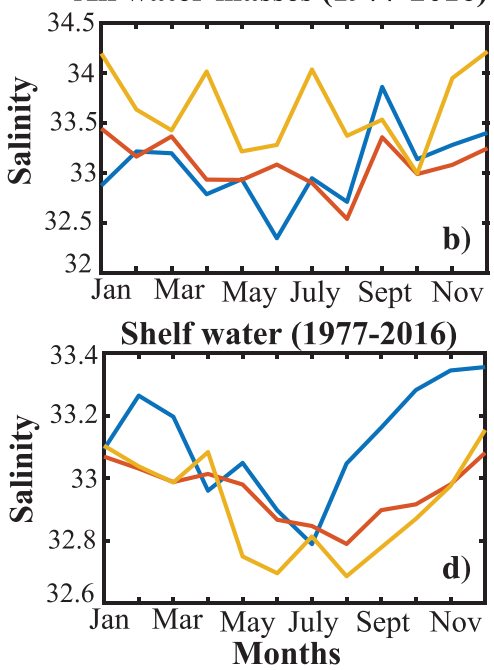

Figure 3. Plots of the monthly climatology for (a) temperature all water masses, (b) salinity all water masses, (c) temperature shelf water only (salinity $<34$ ) and (d) salinity shelf water only (salinity < 34) for the Gulf of Maine (GOM), Georges Bank (GB), and Mid-Atlantic Bight (MAB). The climatology curves are calculated using conductivity-temperature-depth (CTD) data from 19772016.

and GOM were calculated for each year. Seasonal time series plots of the temperature and salinity depict their long-term change and interannual variability (Fig. 3). To quantify the long-term rate of change, a linear function was fit through each time series. The 95\% confidence intervals were computed for each linear trend estimate. The calculation of the confidence intervals takes into account the effective degrees of freedom (DOF), which may differ from the standard estimation of DOF for residuals if the time series data is auto-correlated (Thomson and Emery 2014). Statistically significant results are reported at $P<0.05$.

\section{b. Removing the effect of seasonal sampling bias}

Because the timing of data collection varied from season to season and year to year, there exist seasonal sampling biases that need to be accounted for in the estimation of seasonal averages for temperature and salinity. We used the data on sampling frequency and timing, and the monthly climatological data to calculate the seasonal sampling bias for each season of each year. First, the monthly climatological mean for temperature and salinity were calculated using 40 years of data for each region using the procedure detailed in the previous section (Figs. 3 and 4). The monthly data were then averaged into climatological 


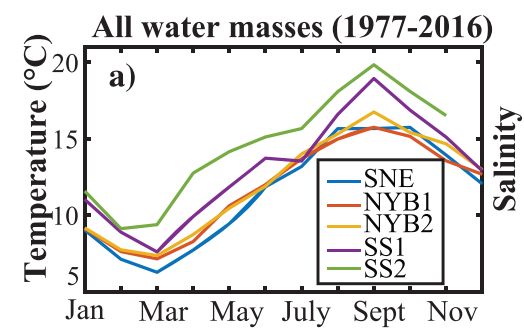

All water masses (1977-2016)
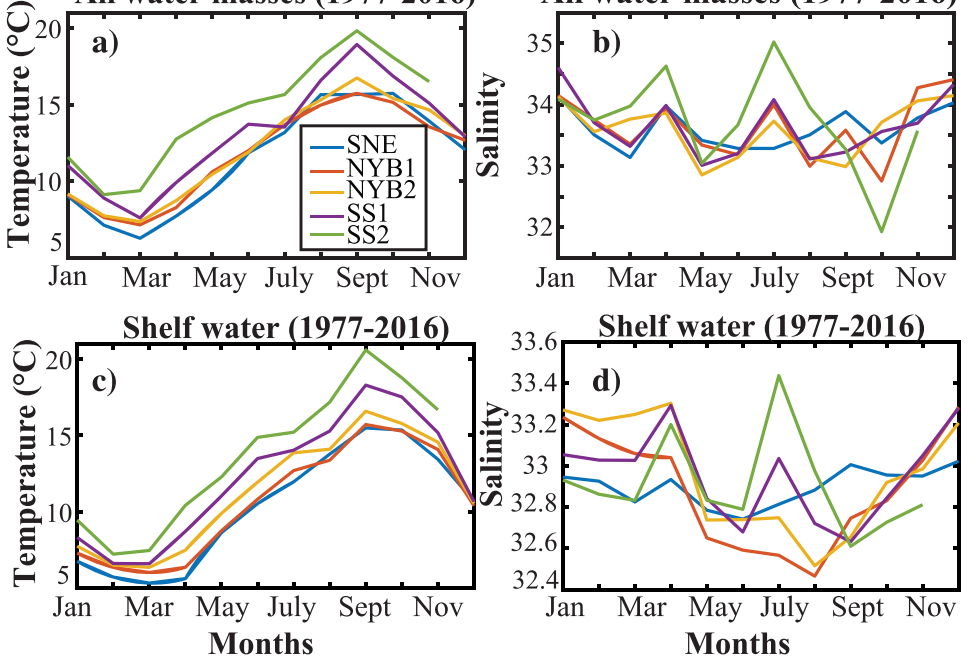

Figure 4. Plots of the monthly climatology for (a) temperature all water masses, (b) salinity all water masses, (c) temperature shelf water only (salinity $<34$ ) and (d) salinity shelf water only (salinity < 34) for the five Mid-Atlantic Bight (MAB) regions. The climatology curves are calculated using conductivity-temperature-depth (CTD) data from 1977-2016.

seasonal means. The three seasons in the study spanned over four months (Winter/SpringJanuary, February, March, April; Summer-May, June, July, August; Fall/Winter-September, October, November, December).

For each season of a given year in each region, the seasonal sampling bias in temperature can be expressed according the following equation:

$$
\Delta T=T_{\text {season }}-\frac{\sum\left(T_{\text {month }} * N_{\text {month }}\right)}{N_{\text {season }}}
$$

where $\Delta \mathrm{T}$ is the temperature sampling bias for a given season, $T_{\text {season }}$ is the seasonal climatological temperature, $T_{\text {month }}$ is the monthly climatological temperature, $N_{\text {month }}$ is the number of CTD station points for a specific month within a given season, and $N_{\text {season }}$ is the total number of CTD station points for a specific season. The summation is over the four months of a specific season in a given year. If the number of station points within each month is the same, then $\Delta \mathrm{T}$, the temperature sampling bias, is 0 . If there were more data collected in the warmer (colder) months than the colder (warmer) months for a given season of a particular year, then $\Delta \mathrm{T}$ would be negative (positive).

The computed temperature sampling bias ( $\Delta \mathrm{T}$ from Equation 4 ) was then added to the average temperatures, calculated according to Section $3 \mathrm{a}$, for each region and each season of each year to obtain the sampling bias-corrected temperatures. The same procedure was 
also applied for removing sampling biases in seasonal estimates of salinity. The linear trend analysis was done on the sampling bias-corrected dataset.

\section{c. Comparison of CTD data with Simple Ocean Data Assimilation}

We applied our analysis methodology to both the CTD data as well as the ocean reanalysis product from Simple Ocean Data Assimilation (SODA) v.3.4.2 (http://www.atmos.umd.edu/ $\sim$ ocean/index_files/soda3.4.2_mn_download.htm) to compare them against each other. Because SODA assimilates the available CTD data, we expect good correlation between the CTD data and SODA reanalysis. SODA is also broadly used by the oceanographic community for various climate analyses and numerical simulations; direct comparison of its reanalysis output with data in the MAB provides useful insight into its skills in this region.

The temperature and salinity trends calculated using the NEFSC data compare favorably with SODA data processed using the same procedures. In general, the SODA data correlates with the observations presented in this paper better in the northern regions of the MAB and during the Winter/Spring and Fall/Winter seasons. However, because the purpose of this study is not to fully validate SODA in the MAB, the comparisons for the different seasons and regions are presented in Appendix A.

\section{d. Investigation of relationship between river discharge and shelf salinity}

To investigate potential causes for interannual and long-term changes in salinity observed in this study, we analyzed the relationship between river discharge and shelf salinity in two major river-influenced regions in the MAB. In particular, we quantified the correlation between shelf salinity in the NYB1 and SS2 regions and the seasonal freshwater discharge from the Hudson River and Chesapeake Bay, respectively. Hudson River is the dominant estuary that directly discharges into NYB1, and Chesapeake Bay outflow discharges into SS2 (Fig. A2).

To obtain the Hudson River discharge, we summed the discharge data from USGS Site 01327750 at Fort Edward, NY and USGS Site 01357500 at Cohoes, NY, following the same procedure as Choi and Wilkin (2007). Site 01327750 is situated along the main stem of the Hudson River and Site 01357500 is situated on Mohawk River, which feeds into the Hudson River (Fig. A2a). Data available from both sites cover our study period from 1977 to 2016 .

To characterize the Chesapeake Bay discharge, we selected the three largest (by volume output) rivers that flow into the bay. These three rivers account for approximately $80 \%$ of the total river discharge into the bay (www.chesapeakebay.net, 2015; Schubel and Pritchard 1987). We used the measured flow data from three sites, one along each river. These three USGS sites were as follows: 01578310 (Susquehanna River), 01646500 (Potomac River), and 02037500 (James River; Fig. A2b). They are the furthest downstream sites in each river with long-term daily discharge values available. The data retrieved from each site spanned from January 1, 1968 until September 11, 2016. To calculate Chesapeake Bay river input, 

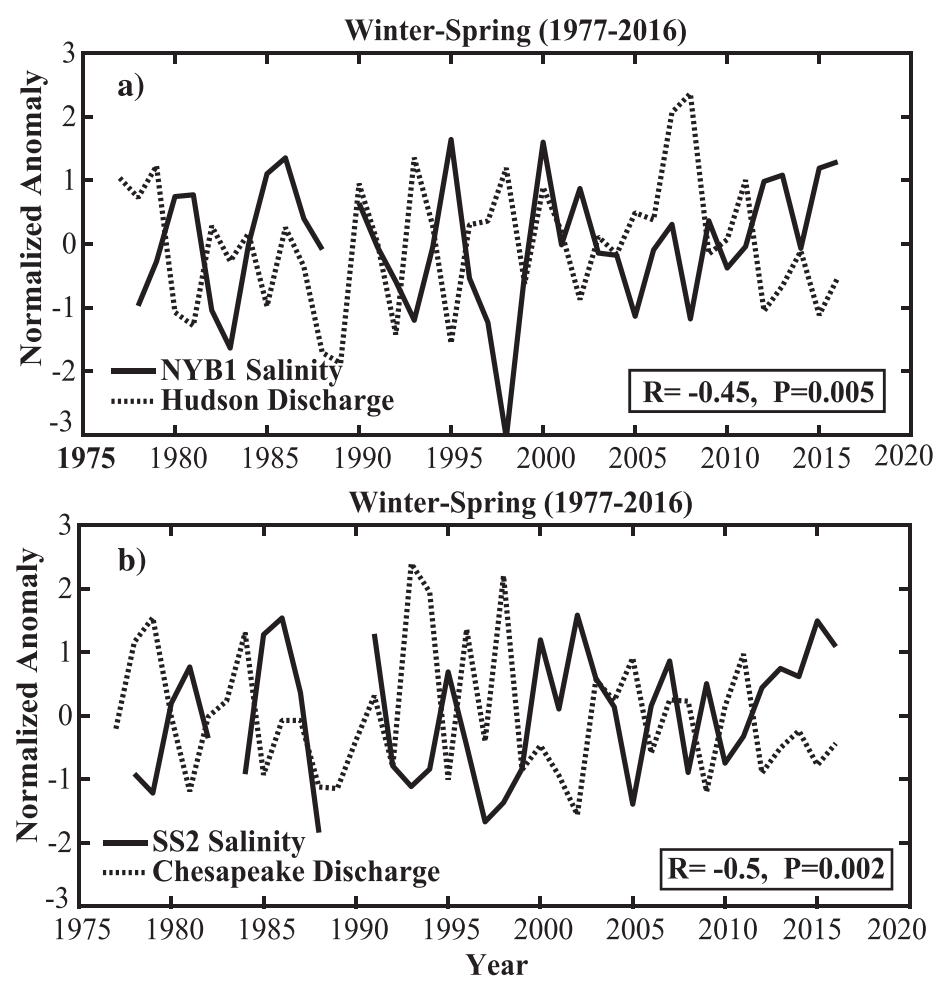

Figure 5. Plots of the standardized anomaly of seasonally averaged shelf salinity and seasonally integrated freshwater transport as functions of time in the (a) New York Bight 1 (NYB1) and (b) Southern Shelf 2 (SS2) regions for the Winter/Spring season from 1977 to 2016. Hudson River discharge is compared with salinity in the NYB1 region and net Chesapeake Bay discharge is compared with salinity in the SS2 region. The correlation for NYB1 and the Hudson River discharge is $R=-0.45$ and correlation for SS2 and the Chesapeake Bay discharge is $R=-0.5$. Both correlations are significant at the $95 \%$ confidence level.

we summed the discharges from the three sites. The final product was divided by 0.8 to estimate the total bay discharge.

For each season of each year, the average discharges for the Hudson River and the Chesapeake Bay were calculated. To illustrate the interannual relationship between seasonallyaveraged river discharge and shelf salinity, the time series of the normalized seasonal discharge of the Hudson River and Chesapeake Bay outflow, and the associated normalized shelf salinities in NYB1 and SS2 were plotted over the study time period (1977-2016; Figs. 5, A3, and A4). The time series data were normalized by first subtracting the linear trends, then dividing the detrended data by their respective standard deviations. Correlation analyses between shelf salinity and seasonally averaged river discharge were performed on 
the annual time scale. We also performed linear fits on the long-term trends of both river discharge and shelf salinity.

\section{Results}

\section{a. Seasonal cycle in temperature and salinity}

The MAB, GB, and GOM had a similar annual cycle for temperature of all water masses on the shelf and shelf water only (Fig. $3 \mathrm{a}$ and c). In general, there was a warming period for approximately six months from March to September and a cooling period for approximately six months from September to March. The GOM waters had the weakest seasonal temperature cycle only varying approximately $4{ }^{\circ} \mathrm{C}$ from March to September. The MAB, on the other hand, had a seasonal temperature cycle almost double that of the GOM varying almost $10{ }^{\circ} \mathrm{C}$ from September to March. This makes sense given that the MAB covers a much larger latitude range that is influenced by a wider array of weather systems and river inputs.

Looking at the five subregions within the MAB (Fig. 4a and c), they each show the same six-month cycling of warming (March to September) and cooling (September to March). The southern regions showed warmer monthly temperatures on average than the northern regions. The minimum and maximum temperatures in each region occurred at approximately the same time around March and September, respectively. This lack of a lag in temperature maxima and minima points towards the dominance of surface heating over along-shelf advection in driving temperature changes across the MAB shelf on an annual time scale. The overall seasonal pattern was the same whether we considered all water masses or just shelf water $(\mathrm{S}<34)$.

The seasonal cycle for salinity in each region is less clear. For all eight regions in this study, there is no apparent seasonal cycle when considering all water masses on the shelf (Figs. 3b and $4 b$ ). However, the shelf water only component for the GOM and GB regions show a decline in salinity from an annual maximum in mid-Winter (January and February) to an annual minimum in mid-Summer (July and August). The MAB, however, begins this decline in shelf water salinity approximately two months later in April (Fig. 3d). This is apparent for the five regions that make up the MAB with the most prominent trend in the New York Bight regions (NYB1 and NYB2; Fig. 4d). Mountain (2003) attributed this annual pattern to the influx of freshwater from the nearby Hudson River. More comprehensive analyses on the influence of Hudson River discharge on NYB1 shelf salinity are detailed in Section 5 below. The southern regions of the MAB (SS1 and SS2) break from this freshening trend in shelf water in the Summer with an abrupt increase in salinity occurring in July (Fig. 4d). This suggests the influences of saline intrusions of offshore water in these regions that are discussed further in Section $5 \mathrm{~b}$.

\section{b. General trends in temperature and salinity}

Figure 6 summarizes the average rates of change in temperature and salinity for all eight regions from 1977 to 2016. The rates of change for both the shelf water only portion 


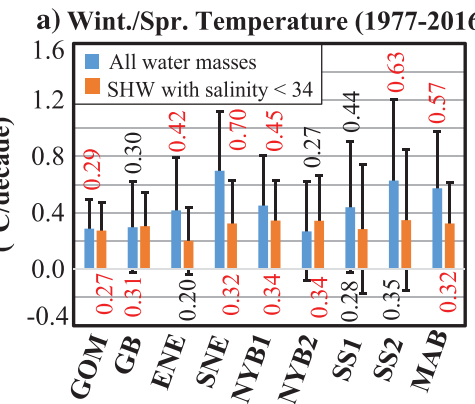

b) Summer Temperature (1977-2016)

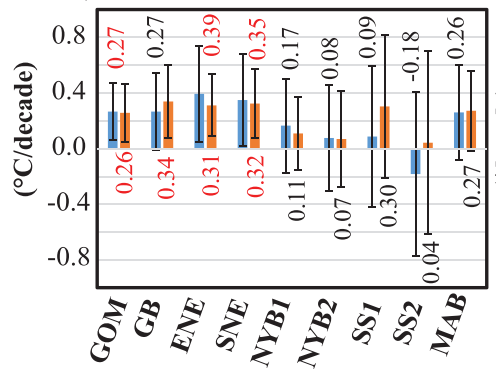

c) Fall/Spr. Temperature (1977-2016)

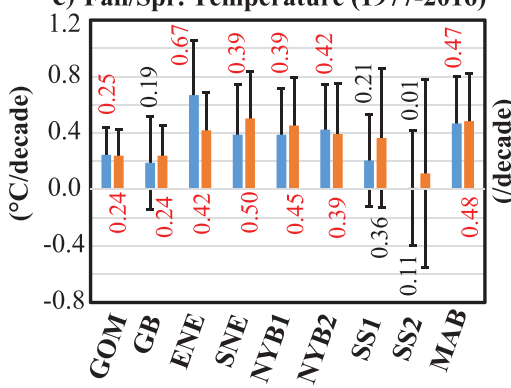

Regions d) Wint./Spr. Salinity (1977-2016)

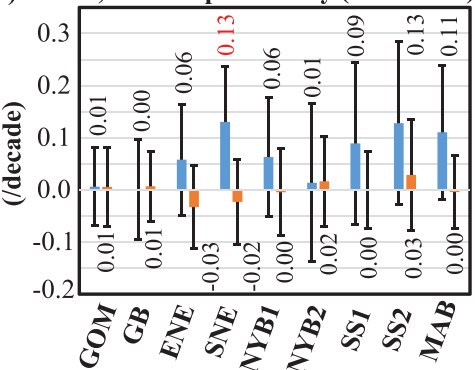

e) Summer Salinity (1977-2016)

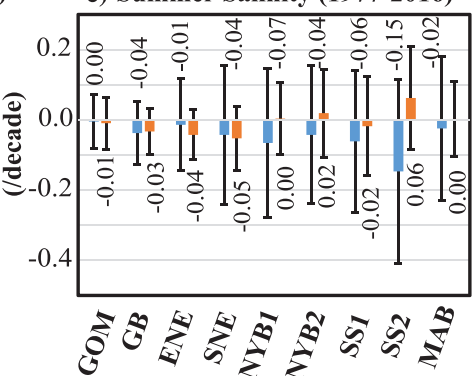

f) Fall/Spr. Salinity (1977-2016)

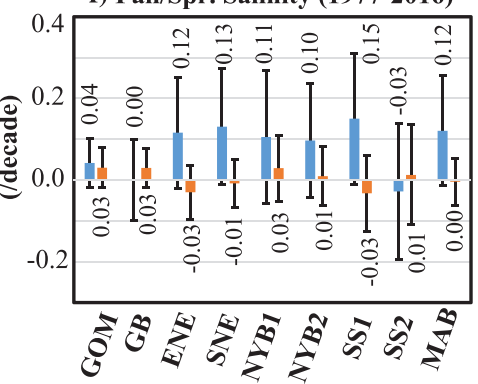

Regions

Figure 6. Plots of the rates of change of temperature and salinity for each season over each region from 1977-2016. The Mid-Atlantic Bight (MAB) region includes Southern New England (SNE), New York Bight 1 (NYB1), New York Bight 2 (NYB2), Southern Shelf 1 (SS1), and Southern Shelf 2 (SS2). The rates (per decade) are the slope of the linear fits to the temperature and salinity time series for each region and season. The blue bars indicate the rates of change calculated for all water masses in the sampling regions and the orange bars indicate the rates for change just for shelf water $(\mathrm{S}<34)$. For each calculated rate, the $95 \%$ confidence interval is shown. Red values denote significant rates of change at the $P<0.05$ level.

$(\mathrm{S}<34)$ as well as all the water masses within the sampling region are separately shown. A number of regions experienced seasonal rates of change that were statistically significant $(P<0.05)$. In the following sections, we will discuss the statistically significant regional and seasonal contributions to these overall trends. 
i. Temperature: $M A B, G B$, and GOM. The MAB, GB, and GOM had significant positive linear trends in temperatures over the 40-year study period from 1977 to 2016 (Fig. 6a-c). The rates of temperature change for all water masses in the GOM were consistently between $0.25{ }^{\circ} \mathrm{C} / \mathrm{decade}$ and $0.29^{\circ} \mathrm{C} / \mathrm{decade}$ for all seasons. The MAB, on the other hand, saw a notably more rapid increase in temperature from September to April (the Winter/Spring and Fall/Winter seasons) with rates between $0.47^{\circ} \mathrm{C} /$ decade and $0.57^{\circ} \mathrm{C} /$ decade (Fig. 6a, c). The rates of warming for the shelf water only component and all water masses across most regions are largely consistent with each other. However, there was a meaningful difference in the warming rates between the two types of water masses in the MAB during the Winter/Spring (January-April) season. Shelf water only warmed at $0.32{ }^{\circ} \mathrm{C} /$ decade whereas all waters masses warmed at $0.57^{\circ} \mathrm{C} / \mathrm{decade}$. This difference suggests an offshore source of heat flux contributing to the long-term warming trend in the MAB.

ii. Temperature: Subregions of the Mid Atlantic Bight. Throughout the study period, most of the significant warming trends over the MAB shelf were concentrated in the northernmost waters (SNE, NYB1, and NYB2) and during the Winter/Spring and Fall/Winter seasons (Fig. 6a and c). The only exception to this was warming observed in Winter/Spring in the southernmost region (SS2; Fig. 6a). Otherwise, in the Winter/Spring, the largest rate of increase was observed in the northernmost region, SNE, at $0.70{ }^{\circ} \mathrm{C} / \mathrm{decade}$ (Fig. 6a). In the Fall/Winter, SNE and the central MAB (NYB1 and NYB2) warmed at similar rates between $0.39{ }^{\circ} \mathrm{C} /$ decade and $0.42{ }^{\circ} \mathrm{C} /$ decade (Fig. 6c). Interestingly, only the SNE region showed a significant warming trend in the Summer season, other MAB sub regions experienced no significant summertime warming (Fig. 6b). This significant difference in seasonal warming rates suggests decreased seasonal temperature differences between winter and summer for most of the MAB.

iii. Salinity: MAB, GB, and GOM. Over the past 40 years (1977-2016), neither the MAB nor any upstream regions have shown significant changes in salinity (Fig. 6). Within the $\mathrm{MAB}$, only the northernmost region (SNE) showed a significant change in salinity in the Winter/Spring season (+0.13/decade) from 1977-2016 (Fig. 6d). None of the individual $\mathrm{MAB}$ regions observed significant trends in the salinity of the shelf water only component.

\section{c. Decadal variability in temperature and salinity}

To study decadal scale change in temperature and salinity, the dataset was divided into two periods. The first was from 1977 to 1999 and the second was from 1999 to 2016 . The first period was the duration of the Mountain (2003) study and the second period covers more recent observations.

Figure 7 summarizes the rates of change of each region and each season during the period from 1977 to 1999. During this shorter time period, the MAB, GB, and GOM continued to warm at about the same rate as over the entire study period. However, all three regions 
a) Wint./Spr. Temperature (1977-1999)

d) Wint./Spr. Salinity (1977-1999)
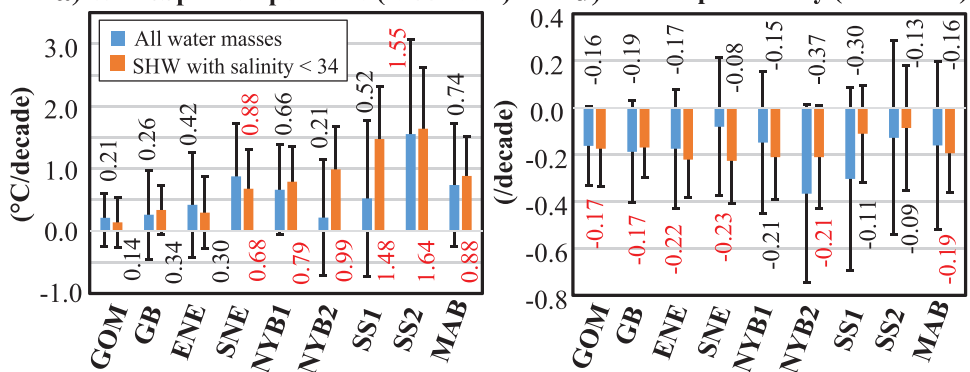

b) Summer Temperature (1977-1999)

e) Summer Salinity (1977-1999)
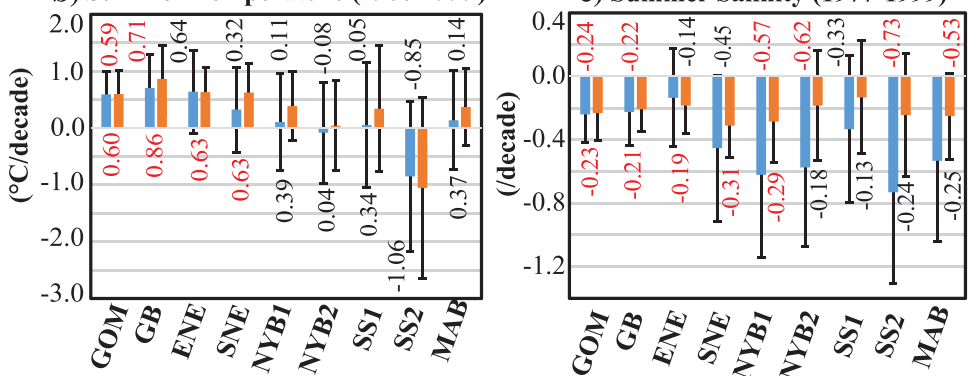

c) Fall/Spr. Temperature (1977-1999)

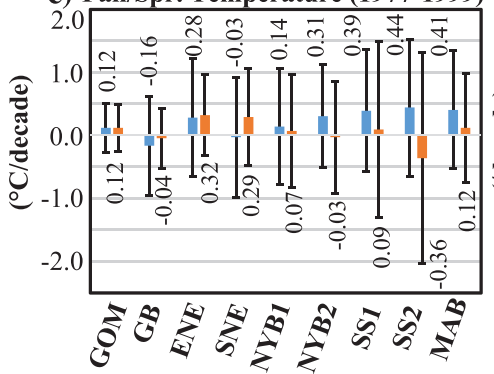

Regions

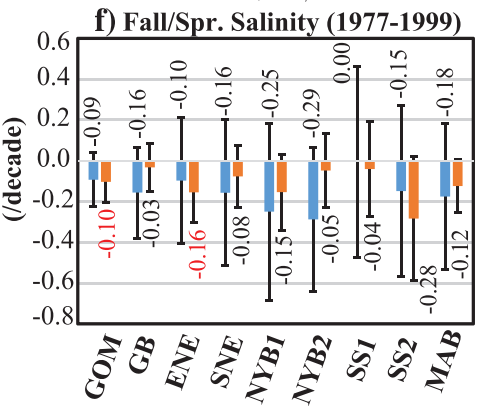

Regions

Figure 7. Same as Figure 6 but for the period from 1977 to 1999.

show a significant change in salinity with amplified freshening in this first time period. Figure 8 summarizes the rates of change over the second period from 1999 to 2016. Most of the temperature and salinity trends in this second period are not significant, but we do see some significant increasing salinity trends in the northern regions of the MAB over this time period. In this section, we provide a comparison of the significant regional and seasonal contributions to these overall trends in both periods. Figure 9 allows for comparison of the magnitude of change across any of the three study periods: 1977-1999, 1999-2016, and 1977-2016. Time series with significant decadal shifts in temperatures and salinity are shown for regions in the MAB (Fig. 10), GB, and GOM (Fig. 11). 
a) Wint./Spr. Temperature (1999-2016)

d) Wint./Spr. Salinity (1999-2016)
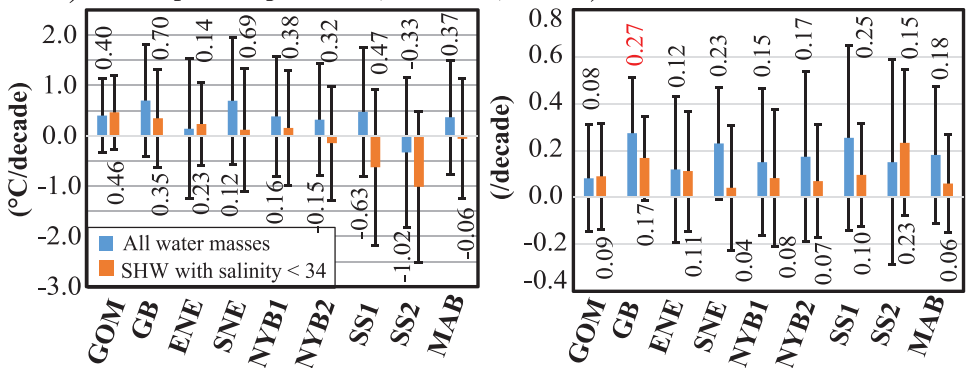

b) Summer Temperature (1999-2016)

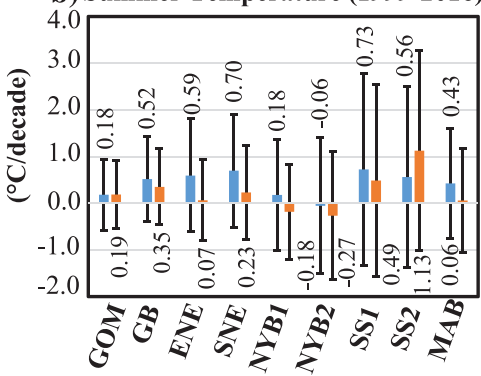

e) Summer Salinity (1999-2016)

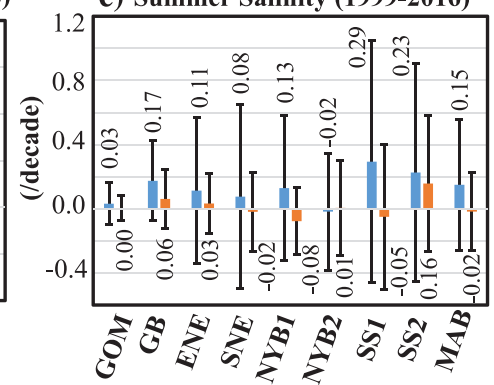

c) Fall/Spr. Temperature (1999-2016)

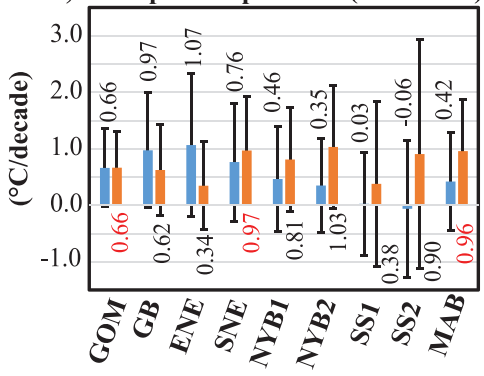

Regions

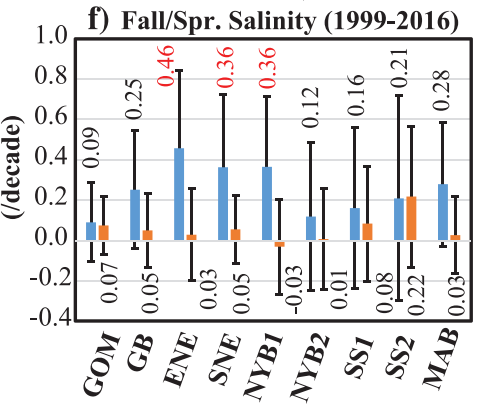

Regions

Figure 8. Same as Figure 6 but for the period from 1999 to 2016.

i. Temperature: $M A B, G B$, and GOM. Although there was significant regional warming in the earlier period (1977-1999) upstream of and throughout the MAB, there were no significant changes in the latter period (1999-2016) especially for all water masses on the shelf (Figs. 7 and 8). The upstream regions (GOM and GB) only showed significant warming in the Summer season for the first period (1977-1999; Fig. 7b). GB experienced $0.71{ }^{\circ} \mathrm{C} / \mathrm{decade}$ of warming for all water masses and $0.86{ }^{\circ} \mathrm{C} /$ decade of warming for the shelf water only component and the GOM experienced approximately $0.6{ }^{\circ} \mathrm{C} /$ decade of warming for both. The MAB, on the other hand, only showed significant warming in the Winter/Spring season for the shelf water only component $\left(0.88^{\circ} \mathrm{C} /\right.$ decade; Fig. $\left.7 \mathrm{a}\right)$. The second period (1999-2016) had no significant warming for all water masses but showed 
1977-2016

\begin{tabular}{|c|c|c|c|c|c|c|c|c|c|}
\hline & & & & - & 016 & & & & \\
\hline & GOM & GB & ENE & SNE & NYB1 & NYB2 & SS1 & SS2 & МАB \\
\hline Temperatu & $\mathrm{re}\left({ }^{\circ} \mathrm{C} / \mathrm{de}\right.$ & cade) & & & & & & & \\
\hline Wint/Spr & 0.29 & 0.30 & 0.42 & 0.70 & 0.45 & 0.27 & 0.44 & 0.63 & 0.57 \\
\hline Summer & 0.27 & 0.27 & 0.39 & 0.35 & 0.17 & 0.08 & 0.09 & -0.18 & 0.26 \\
\hline Fall/Wint & 0.25 & 0.19 & 0.67 & 0.39 & 0.39 & 0.42 & 0.21 & 0.01 & 0.47 \\
\hline SHW Tem & iture ( & C/deca & ide) & & & & & & \\
\hline Wint/Spr & 0.27 & 0.31 & 0.20 & 0.32 & 0.34 & 0.34 & 0.28 & 0.35 & 0.32 \\
\hline Summer & 0.26 & 0.34 & 0.31 & 0.32 & 0.11 & 0.07 & 0.30 & 0.04 & 0.27 \\
\hline Fall/Wint & \begin{tabular}{l|l}
0.24 \\
\end{tabular} & 0.24 & 0.42 & 0.50 & 0.45 & 0.39 & 0.36 & 0.11 & 0.48 \\
\hline Salinity $(/$ & ecade) & & & & & & & & \\
\hline Wint/Spr & 0.01 & 0.00 & 0.06 & 0.13 & 0.06 & 0.01 & 0.09 & 0.13 & 0.11 \\
\hline Summer & 0.00 & -0.04 & -0.01 & -0.04 & -0.07 & -0.04 & -0.06 & -0.15 & -0.02 \\
\hline Fall/Wint & 0.04 & 0.00 & 0.12 & 0.13 & 0.11 & 0.10 & 0.15 & -0.03 & 0.12 \\
\hline SHW Salin & ity (/decad & & & & & & & & \\
\hline Wint/Spr & 0.01 & 0.01 & -0.03 & -0.02 & 0.00 & 0.02 & 0.00 & 0.03 & 0.00 \\
\hline Summer & -0.01 & -0.03 & -0.04 & -0.05 & 0.00 & 0.02 & -0.02 & 0.06 & 0.00 \\
\hline Fall/Wint & 0.03 & 0.03 & -0.03 & -0.01 & 0.03 & 0.01 & -0.03 & 0.01 & 0.00 \\
\hline & & & & $1977-19$ & 999 & & & & \\
\hline Temperatu & $\left({ }^{\circ} \mathrm{C} / \mathrm{de}\right.$ & cade) & & & & & & & \\
\hline Wint/Spr & 0.21 & 0.26 & 0.42 & 0.88 & 0.66 & 0.21 & 0.52 & 1.55 & 0.74 \\
\hline Summer & 0.59 & 0.71 & 0.64 & 0.32 & 0.11 & -0.08 & 0.05 & -0.85 & 0.14 \\
\hline Fall/Wint & 0.12 & -0.16 & 0.28 & -0.03 & 0.14 & 0.31 & 0.39 & 0.44 & 0.41 \\
\hline SHW Tem & ature ( & $\mathrm{C} / \mathrm{deca}$ & ide) & & & & & & \\
\hline Wint/Spr & 0.14 & 0.34 & 0.30 & 0.68 & 0.79 & 0.99 & 1.48 & 1.64 & 0.88 \\
\hline Summer & 0.60 & 0.86 & 0.63 & 0.63 & 0.39 & 0.04 & 0.34 & -1.06 & 0.37 \\
\hline Fall/Wint & 0.12 & -0.04 & 0.32 & 0.29 & 0.07 & -0.03 & 0.09 & -0.36 & 0.12 \\
\hline Salinity (/ & cade) & & & & & & & & \\
\hline Wint/Spr & -0.16 & -0.19 & -0.17 & -0.08 & -0.15 & -0.37 & -0.30 & -0.13 & -0.16 \\
\hline Summer & -0.24 & -0.22 & -0.14 & -0.45 & -0.62 & -0.57 & -0.33 & -0.73 & -0.53 \\
\hline Fall/Wint & -0.09 & -0.16 & -0.10 & -0.16 & -0.25 & -0.29 & 0.00 & -0.15 & -0.18 \\
\hline SHW Sal & (/decad & & & & & & & & \\
\hline Wint/Spr & -0.17 & -0.17 & -0.22 & -0.23 & -0.21 & -0.21 & -0.11 & -0.09 & -0.19 \\
\hline Summer & -0.23 & -0.21 & -0.19 & -0.31 & -0.29 & -0.18 & -0.13 & -0.24 & -0.25 \\
\hline Fall/Wint & -0.10 & -0.03 & -0.16 & -0.08 & -0.15 & -0.05 & -0.04 & -0.28 & -0.12 \\
\hline & & & & & & & & & \\
\hline
\end{tabular}

\begin{tabular}{|c|c|c|c|c|c|c|c|c|c|}
\hline \multicolumn{10}{|c|}{ Temperature $\left({ }^{\circ} \mathrm{C} / \mathrm{decade}\right)$} \\
\hline Wint/Spr & 0.40 & 0.70 & 0.14 & 0.69 & 0.38 & 0.32 & 0.47 & -0.33 & 0.37 \\
\hline Summer & 0.18 & 0.52 & 0.59 & 0.70 & 0.18 & -0.06 & 0.73 & 0.56 & 0.43 \\
\hline Fall/Wint & 0.66 & 0.97 & 1.07 & 0.76 & 0.46 & 0.35 & 0.03 & -0.06 & 0.42 \\
\hline \multicolumn{10}{|c|}{ SHW Temperature $\left({ }^{\circ} \mathrm{C} /\right.$ decade $)$} \\
\hline Wint/Spr & 0.46 & 0.35 & 0.23 & 0.12 & 0.16 & -0.15 & -0.63 & -1.02 & -0.06 \\
\hline Summer & 0.19 & 0.35 & 0.07 & 0.23 & -0.18 & -0.27 & 0.49 & 1.13 & 0.06 \\
\hline Fall/Wint & 0.66 & 0.62 & 0.34 & 0.97 & 0.81 & 1.03 & 0.38 & 0.90 & 0.96 \\
\hline \multicolumn{10}{|c|}{ Salinity (/decade) } \\
\hline Wint/Spr & 0.08 & 0.27 & 0.12 & 0.23 & 0.15 & 0.17 & 0.25 & 0.15 & 0.18 \\
\hline Summer & 0.03 & 0.17 & 0.11 & 0.08 & 0.13 & -0.02 & 0.29 & 0.23 & 0.15 \\
\hline Fall/Wint & 0.09 & 0.25 & 0.46 & 0.36 & 0.36 & 0.12 & 0.16 & 0.21 & 0.28 \\
\hline \multicolumn{10}{|c|}{ SHW Salinity (/decade) } \\
\hline Wint/Spr & 0.09 & 0.17 & 0.11 & 0.04 & 0.08 & 0.07 & 0.10 & 0.23 & 0.06 \\
\hline Summer & 0.00 & 0.06 & 0.03 & -0.02 & -0.08 & 0.01 & -0.05 & 0.16 & -0.02 \\
\hline \multirow[t]{7}{*}{ Fall/Wint } & 0.07 & 0.05 & 0.03 & 0.05 & -0.03 & 0.01 & 0.08 & 0.22 & 0.03 \\
\hline & & \multicolumn{3}{|c|}{ Temperature } & \multicolumn{3}{|c|}{ Salinity } & & \\
\hline & & \multicolumn{3}{|c|}{$x>0.5^{\circ} \mathrm{C}$} & \multicolumn{3}{|c|}{$x>0.15$} & & \\
\hline & & \multicolumn{3}{|c|}{$0.2<\mathrm{x}<0.5^{\circ} \mathrm{C}$} & \multicolumn{3}{|c|}{$0.05<\mathrm{x}<0.15$} & & \\
\hline & & \multicolumn{3}{|c|}{$0.2>\mathrm{x}>-0.2^{\circ} \mathrm{C}$} & \multicolumn{3}{|c|}{$0.05>x>-0.05$} & & \\
\hline & & \multicolumn{3}{|c|}{$-0.2>x>-0.5^{\circ} \mathrm{C}$} & \multicolumn{3}{|c|}{$-0.05>x>-0.15$} & & \\
\hline & & \multicolumn{3}{|c|}{$x<-0.5^{\circ} \mathrm{C}$} & \multicolumn{3}{|c|}{$x<-0.15$} & & \\
\hline
\end{tabular}

Figure 9. The rates of change of temperature and salinity for all water masses and shelf water only (S < 34). The values for each season over each region from 1977-2016, 1977-1999, and 19992016 are shown. The Mid-Atlantic Bight (MAB) regions include Southern New England (SNE), New York Bight 1 (NYB1), New York Bight 2 (NYB2), Southern Shelf 1 (SS1), and Southern Shelf 2 (SS2). The rates (per decade) are the slope of the linear fits to the temperature and salinity time series for each region and season. Significant rates of change are boxed and bolded. The boxes are color coded to denote scale of the change and facilitate comparison between time periods with red indicating a large increase, pink a small increase, white negligible change, light blue a small decrease, and dark blue a large decrease. 

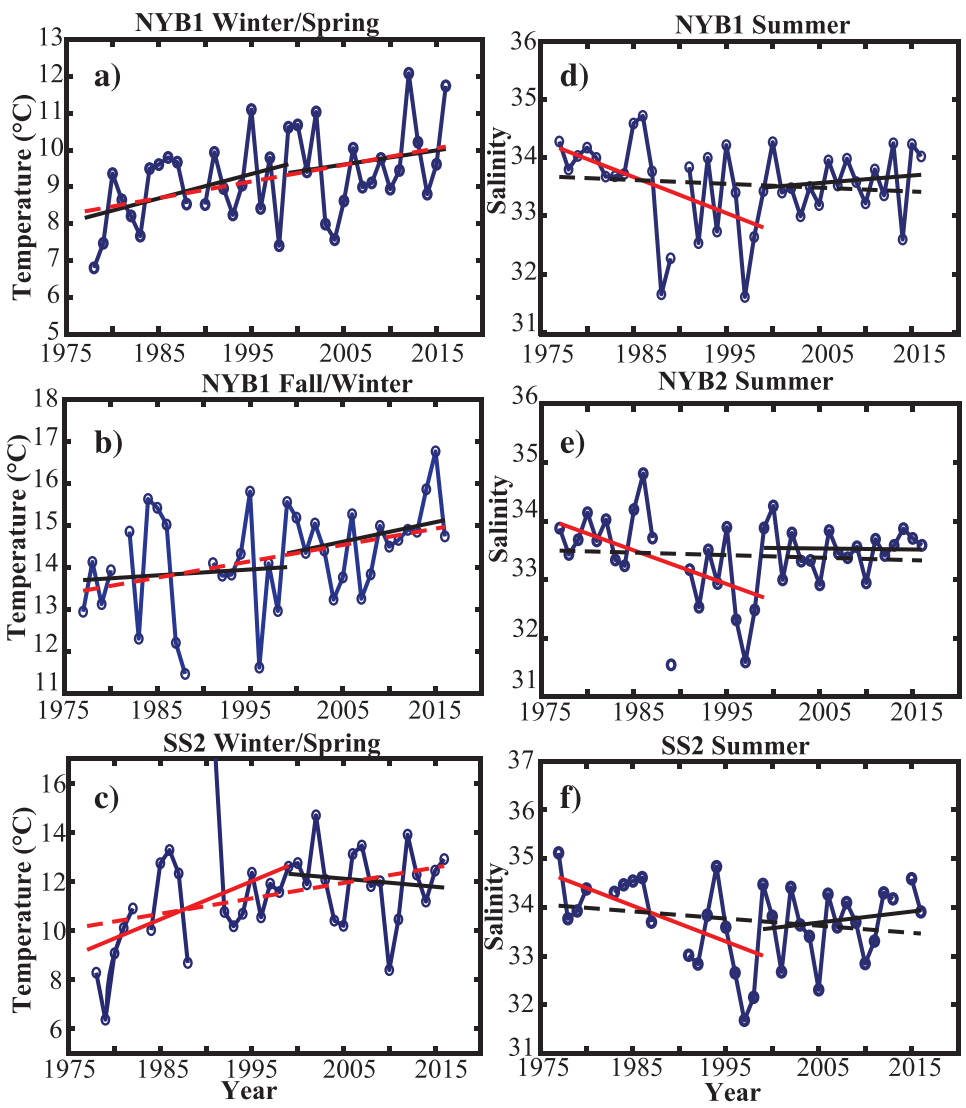

Figure 10. Plots of temperature and salinity for all water masses as a function of time from 1977 to 2016 for select regions and seasons. The linear trend lines for the entire 40-year time span (dashed lines) and for each period (1977-1999 and 1999-2016 solid lines) are shown. Statistically significant (at $95 \%$ confidence level) linear trends are plotted in red.

significant shelf water warming in the Fall/Winter season for the GOM $\left(0.66{ }^{\circ} \mathrm{C} / \mathrm{decade}\right)$ and MAB $\left(0.96^{\circ} \mathrm{C} /\right.$ decade; Fig. $\left.8 \mathrm{c}\right)$.

ii. Temperature: Subregions of the MAB. All five regions in the MAB showed significant warming in the Winter/Spring season for the shelf water only component during the first period (1977-1999; Fig. 7a). The warming trends increased southward with the magnitude increasing from $0.68{ }^{\circ} \mathrm{C} /$ decade in SNE to $1.64{ }^{\circ} \mathrm{C} /$ decade in SS2. Of the five regions in the MAB, only SNE and SS2 showed significant trends in both shelf water and all water masses on the shelf. No other season showed significant temperature trends during this period. 

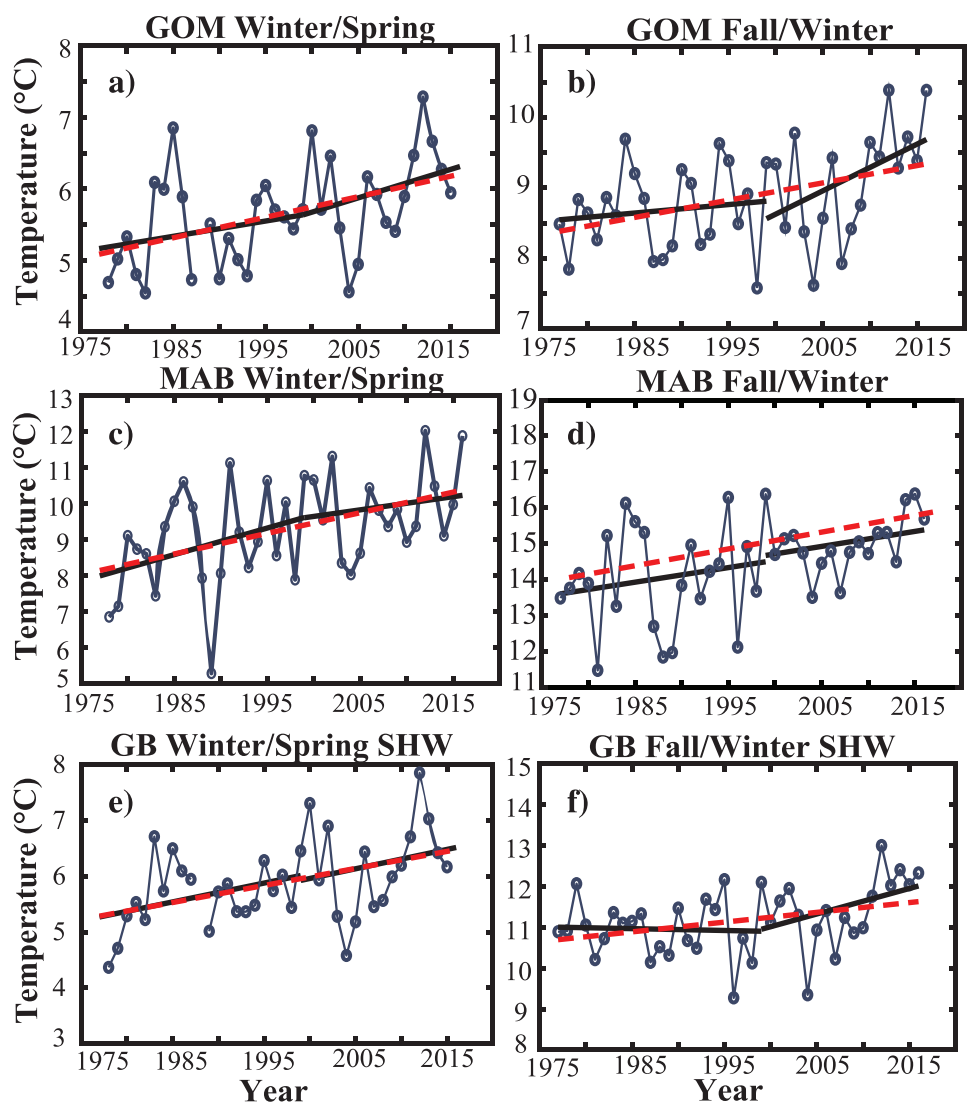

Figure 11. Plots of temperature for all water masses (a-d) and shelf water only (e, f) as a function of time from 1977 to 2016 for select regions and seasons. The linear trend lines for the entire 40-year time span (dashed lines) and for each period (1977-1999 and 1999-2016 solid lines) are shown. Statistically significant (at $95 \%$ confidence level) linear trends are plotted in red.

Within the MAB, there was similarly no significant temperature trends in the second period for all water masses. The northernmost region (SNE) shows the only significant trend, warming at $0.97{ }^{\circ} \mathrm{C} /$ decade during the Fall/Winter season (Fig. 8c). It is possible that the 17 years of data in the second period (compared to 22 years in the first period) may not be enough to establish potentially significant trends.

iii. Salinity: $M A B, G B$, and GOM. Salinity trends from 1977 until 1999 vary dramatically from salinity trends from 1999 to 2016. During the first period, we see a general freshening throughout the MAB and upstream locations. The freshening trend switches to an increase in salinity during the second period (Fig. 9). The shelf water in the GOM freshened significantly over the first period in every season (Fig. 7d-f). In GB, shelf water freshened in 
the Winter/Spring and Summer seasons. In the MAB, significant freshening of shelf water was observed only during the Winter/Spring (Fig. 7d).

When considering all water masses during the first period, the MAB, GB, and GOM freshened significantly in the Summer season at $-0.53 /$ decade, $-0.22 /$ decade, and $-0.24 /$ decade, respectively (Fig. 7e). Given that the freshening in the MAB is over double the freshening upstream in the GB and GOM, it is likely that much of this freshening is a result of local inputs such as rivers as opposed to advective influences.

In contrast, during the second period, these freshening trends disappeared and there were no significant changes in salinity in any region except for the GB, which showed a significant increase in salinity in the Winter/Spring season at 0.27/decade (Fig. 8d).

iv. Salinity: Subregions of the MAB. Looking at the central (NYB1, NYB2) and southern MAB (SS2) regions for the first period (1977-1999), we observed significant freshening during the Summer season for all water masses on the shelf (Fig. 7e). Interestingly, these regions are heavily influenced by riverine inputs. During the second period, many of these same regions saw a complete flip in the trend to an increase in salinity. SNE and NYB1 both experienced significant increases in salinity (0.36/decade) in the Fall/Winter season for all water masses during the second period (Fig. 8f).

When considering shelf water only, the trends within the MAB show significant freshening in the first period in the northernmost regions, SNE and NYB1. These two regions showed significant freshening in the Winter/Spring and Summer season varying from -0.21 to $-0.31 /$ decade (Fig. $7 d-e$ ). However, for the second period, there were no significant changes in shelf water salinity in any region of the MAB.

\section{d. Decadal changes in temperature and salinity profiles}

Using CTD data from the outer shelf, we compared the average water column structure between the two periods of study. Figures 12-14 display profiles of the average temperature and salinity for both the first (1977-1999) and second (1999-2016) periods in all mid-shelf and outer-shelf stations in MAB regions as well as the greater MAB, GB, and GOM. Stations were included in these profile calculations if they were situated in at least $50 \mathrm{~m}$ in depth, and all calculations were cut off at $90 \mathrm{~m}$ deep.

The temperature profiles show warmer temperature occurring in the second period (19992016) throughout the water column as compared with the first period (1977-1999). However, the depth(s) of these significant differences in temperature vary depending on the location on the shelf. In general, the northern regions (GOM through SNE) show significantly warmer water during the second period (1999-2016) in the upper water column (upper $30 \mathrm{~m}$; Figs. 14 and A4). Whereas, the southern regions of the MAB (NYB2-SS2) show significantly warmer water below $60 \mathrm{~m}$ (Figs. 12c and 13a and c). The NYB1 region represents the transition between these two patterns with significantly warmer temperatures in the second period occurring throughout the water column (Fig. 12a). Both the northern and southern region 

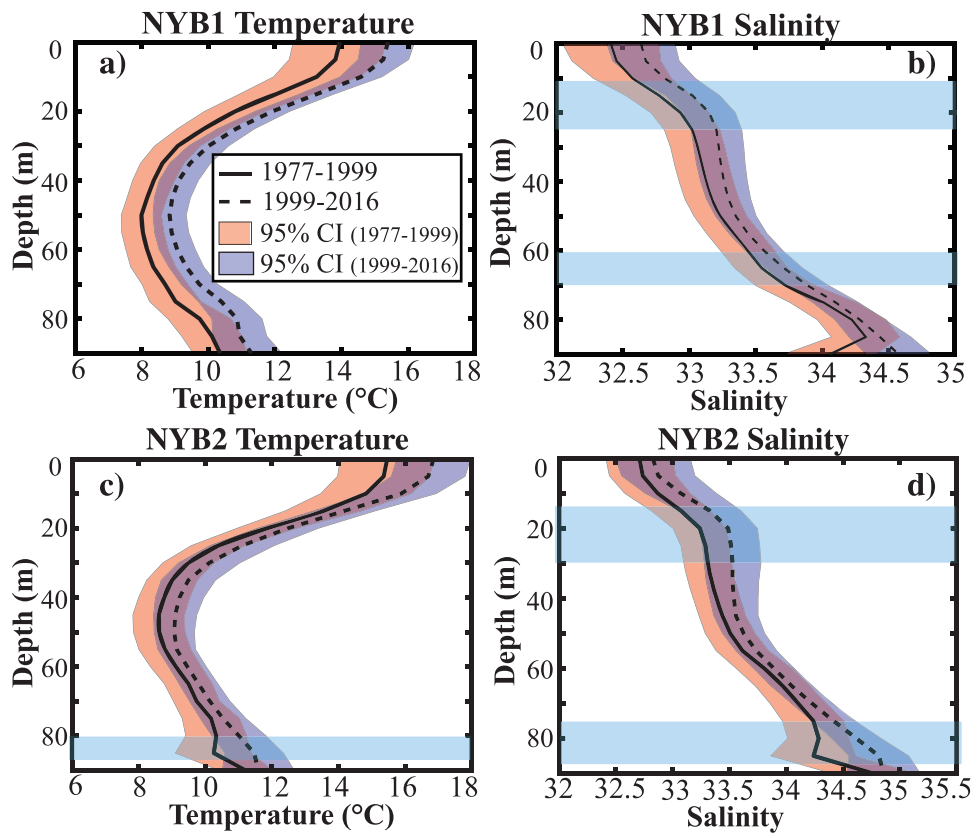

Figure 12. Profiles of salinity and temperature (stations extending from at least $50 \mathrm{~m}$ to $90 \mathrm{~m}$ in depth) in the New York Bight 1 (NYB1) (a, b) and New York Bight 2 (NYB2) (c, d) from 1977-1999 (solid line) and from 1999-2016 (dashed line). The 95\% confidence intervals around each profile are shown in red and blue for the first and second period, respectively. Blue horizontal bars highlight the water depths with important significant differences between the first and second period.

patterns are clearly displayed in the profile plot for the entire MAB (Fig. 14). It shows a combination of the two warming patterns with significant warmer water in both the upper $30 \mathrm{~m}$ and below $60 \mathrm{~m}$ during the second period.

These results suggest that the northern regions on the shelf over the past decade have experienced more warming in the upper water column, likely due to a combination of airsea exchange over these northern regions and thermohaline intrusions at the surface and the pycnocline. The southern regions on the other hand provide evidence for a decadal scale increase in the number of bottom water intrusions. Indeed, midlevel and bottom intrusions in the MAB typically occur 15-30 m and below $60 \mathrm{~m}$ depth, respectively (Bigelow and Sears 1935; Lentz 2003; Gong 2010).

The salinity profiles for many of these regions showed that the outer-shelf water column was saltier for the second period than the first. This is consistent with the decadal trends in salinity discussed earlier. Although the regions north of the MAB don't have many significant differences in salinity between the two periods, the whole MAB salinity profile had significantly higher salinity during the second period at depths of 15-30 m and below $60 \mathrm{~m}$ (Fig. 14). Both NYB regions confirm these differences in salinity also showing significantly 

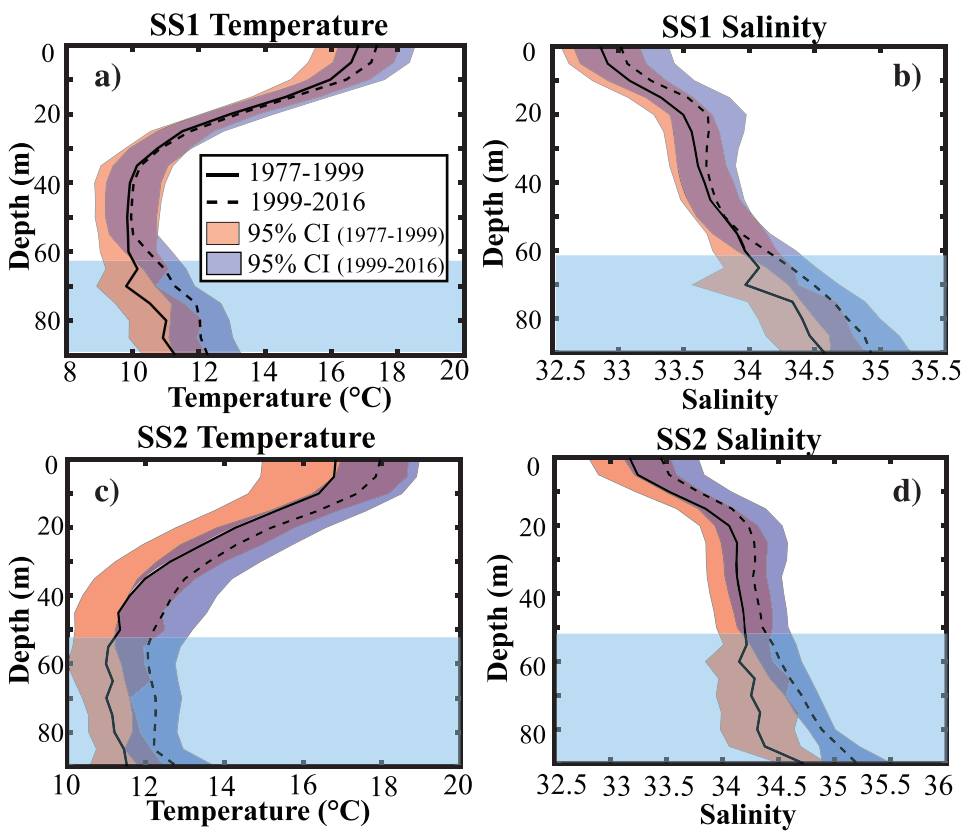

Figure 13. Profiles of salinity and temperature (stations extending from at least $50 \mathrm{~m}$ to $90 \mathrm{~m}$ in depth) in the Southern Shelf 1 (SS1) (a, b) and Southern Shelf 2 (SS2) (c, d) from 1977-1999 (solid line) and from 1999-2016 (dashed line). The 95\% confidence intervals around each profile are shown in red and blue for the first and second period, respectively. Blue horizontal bars highlight the water depths with important significant differences between the first and second period.

increased salinity during the second period near the pycnocline $(15-30 \mathrm{~m})$ and below $60 \mathrm{~m}$. The southern MAB regions (SS1 and SS2) only show these bottom level salinity changes with significantly increased salinity during the second period below $60 \mathrm{~m}$.

The ENE region showed an intriguing result where significantly increased temperature in the second period was found above $50 \mathrm{~m}$ depth, but below $80 \mathrm{~m}$ it was significantly cooler and fresher in the second period (Fig. A5c). Although factors such as a decline in the number of bottom water intrusions may have played a role, it is beyond the scope of this paper to investigate the detailed circulation and dynamics of deep shelf water over Eastern New England.

\section{Discussion}

\section{a. General trends in the Mid-Atlantic Bight}

$i$. Temperature. In general, calculated temperature trends across the MAB and the northern regions from 1977 to 2016 are consistent with other recent studies of ocean temperature trends. From 1984-2011, the GOM surface temperature warmed at a rate of $0.26^{\circ} \mathrm{C} / \mathrm{decade}$ 

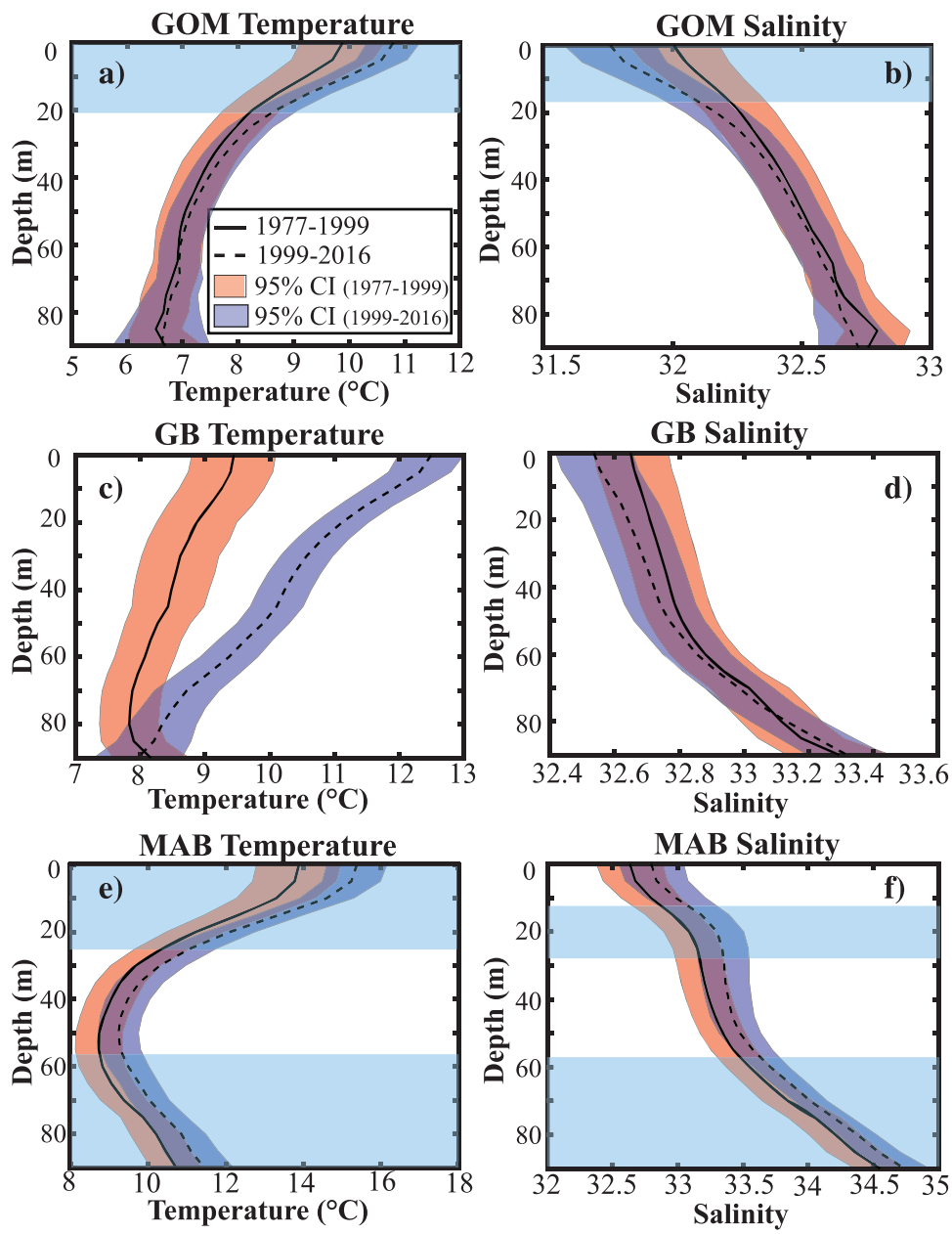

Figure 14. Profiles of salinity and temperature (stations extending from at least $50 \mathrm{~m}$ to $90 \mathrm{~m}$ in depth) in the Gulf of Maine (GOM) (a, b), Georges Bank (GB) (c, d), and Mid-Atlantic Bight (MAB) (e, f) from 1977-1999 (solid line) and from 1999-2016 (dashed line). The 95\% confidence intervals around each profile are shown in red and blue for the first and second period, respectively. Blue horizontal bars highlight the water depths with important significant differences between the first and second period.

(Mills et al. 2013), which is very similar to our observed depth-averaged warming trend of $0.27^{\circ} \mathrm{C} /$ decade in the GOM from 1977-2016. Forsyth et al. (2015) reported depth-averaged temperature measurements from the CMV Oleander dataset of $0.26 \pm 0.01{ }^{\circ} \mathrm{C} /$ decade from 1977 to 2013. Our dataset yields comparable warming trends to Forsyth et al. (2015) at $0.3 \pm 0.3{ }^{\circ} \mathrm{C} /$ decade when calculated over the same time span (1977-2013) over the NYB1 region, which encompasses most of the span of the CMV Oleander data. 
On the longer centennial time scale, air temperature warming plays a larger role in shaping these ocean temperature trends. Shearman and Lentz (2010) reported an oceanic warming trend from 1875 to 2007 for the $\mathrm{MAB}$ of $0.7^{\circ} \pm 0.3^{\circ} \mathrm{C}(100 \mathrm{yr})^{-1}$. Corresponding analysis of surface air temperature using GISS data in the U.S. (1880-2007) indicated a comparable warming trend of $0.6^{\circ} \mathrm{C}(100 \mathrm{yr})^{-1}$ (Fig. A6). This suggests that the long-term MAB shelf water temperature trend is primarily driven by the atmosphere, and that both atmospheric and oceanic temperatures have undergone much faster warming since the late 1970s compared to the centennial trends.

However, when compared to nearby air temperature trends over the past 40 years, our $\mathrm{MAB}$ ocean temperature trends indicated stronger warming than the atmosphere. From 1977 to 2016, the air temperature warming over the U.S. continent was $0.28^{\circ} \mathrm{C} /$ decade based on NASA GISS Surface Air Temperature Analysis (Fig. A6; https://data.giss.nasa.gov/gistemp/ graphs/, 2017), which is $35 \%$ less than the observed ocean warming over the MAB shelf (at $0.43^{\circ} \mathrm{C} /$ decade).

A possible explanation for the increased warming trends in the MAB water column as compared to atmospheric warming is that they are due to amplified atmospheric temperature increase at upstream locations in the Arctic and Labrador Sea (i.e., polar amplification) and the advection of the warmer water into the MAB from these northern sources. Shearman and Lentz (2010) noted local differences between atmosphere and ocean warming with the sea surface temperature (SST) increase from 1875 to 2007 across the MAB and GOM exceeding the local atmospheric warming in these regions by a factor of 1.8-2.5. They also observed that the rate of air temperature increase over the Labrador Sea was $1.1^{\circ} \pm 0.4^{\circ} \mathrm{C}$ $(100 \mathrm{yr})^{-1}$ compared to a temperature increase of $0.4^{\circ} \pm 0.4^{\circ} \mathrm{C}(100 \mathrm{yr})^{-1}$ over the US Northeast coast (Shearman and Lentz 2010). However, it is clear that upstream advection cannot be the full story given that the observed warming trends in GB $\left(0.25^{\circ} \mathrm{C} / \mathrm{dec}\right.$ de $)$ and the GOM $\left(0.27{ }^{\circ} \mathrm{C} /\right.$ decade $)$ are comparable to atmospheric warming over the US continent $\left(0.28{ }^{\circ} \mathrm{C} /\right.$ decade based on NASA GISS $)$.

In addition, our results highlight significant variability of seasonal temperature trends in the MAB that also cannot be explained solely by air temperature trends. We observed the strongest and most significant warming results in the MAB from 1977-2016 during the Winter/Spring (Jan-Apr, $0.57{ }^{\circ} \mathrm{C} /$ decade) and the Fall/Winter (Sep-Dec, $0.47^{\circ} \mathrm{C} /$ decade) seasons. While in the Summer season, the MAB experienced no significant warming over the same period. This seasonal pattern of increased warming in the winter is consistent with previous studies (Shearman and Lentz 2010; Connolly and Lentz 2014). Although the rate of northern hemisphere air temperature increase during the Spring/Fall/Winter seasons $\left(0.32{ }^{\circ} \mathrm{C} /\right.$ decade, NASA GISS $)$ is on average $17 \%$ faster than the Summer season $\left(0.27{ }^{\circ} \mathrm{C} /\right.$ decade $)$, it is not a sufficient difference to explain the observed difference in oceanic seasonal warming trends. This suggest that the much faster warming trend in the MAB during the Winter/Spring season is likely driven by additional factors such as alongshelf advection of warmer shelf water and shoreward intrusion of warm offshore water. In summary, the long-term annualized temperature change over the 40 years is consistent with 
being driven by atmospheric warming, and along-shore advection and offshore heat flux seem to make a nontrivial impact on the variability of the seasonal trends.

ii. Salinity. From 1977 to 2016, the regionally averaged salinity showed no significant changes throughout the GOM, GB, and MAB. This is predominantly a result of high interannual variability in shelf salinity over the past 40 years. On the interannual time scale, the variability in freshwater discharge from the major estuaries in the MAB is expected to contribute to the shelf salinity variability. We computed the standardized anomaly (detrended first then normalized by the standard deviation) for the seasonal integrated freshwater discharge for the Hudson River and Chesapeake Bay outflow and the shelf salinity for NYB1 and SS2. There were significant anticorrelations observed between the two sets of time series with correlation coefficients $R=-0.45$ for the Hudson River and NYB1, and $R=-0.50$ for the Chesapeake Bay and SS2 during the Winter/Spring season when the climatological seasonal discharge is maximum (Fig. 5). The Summer season did not display significant relationships over the entire period (Fig. A3). During the Fall/Winter season, SS2 and Chesapeake Bay discharge were also significantly anticorrelated $(R=-0.45$; Fig. A4).

The result that discharge and shelf salinity from the same season are significantly anticorrelated might be somewhat surprising given that it can take 100-200 days for freshwater to flow from upstream rivers in the Chesapeake Bay to the shelf (Du and Shen 2016). Looking at river discharge and surface salinity values in the MAB, Whitney (2010) observed a one to two-month lag between peak river discharge and minimum shelf salinity. We showed in Figure 3 that the MAB shelf reached minimum salinity in the early summer (May and June) consistent with the time scale of advection. Because of these results, one might expect that the correlation would be highest between spring discharge and summer shelf salinity. Correlation analysis of Winter/Spring discharge in the Hudson River and Chesapeake Bay and Summer NYB1 and SS2 salinity show that the correlations were lower than those from the same season (Winter/Spring SS2 salinity; Fig. A7).

The expected correlation between spring discharge and summer shelf salinity may not be significant if there are other processes (i.e., tidal and wind-driven mixing and intrusion of offshore water masses) that exert stronger control on shelf salinity variability and overcome the local river signal. During the weakly stratified Winter/Spring seasons, we expect that the major driver of shelf salinity is local river discharge due to the seasonal occurrence of a strong shelfbreak front along the entire MAB that separates the shelf water from offshore waters (Linder and Gawarkiewicz 1998; Voorhis et al. 1976). During the stratified Summer/Fall seasons, when isopycnals at the shelfbreak are mostly flat, saline intrusions of offshore water onto the MAB shelf are common occurrences (Lentz 2003; Bigelow and Sears 1935). The most intense intrusions are typically found in mid- to late summer and early fall in the MAB (Gong et al. 2010). Bottom intrusions contribute to approximately half of the salt, and midwater column and surface intrusions contribute the remaining half (Gong et al. 2010). The strong influence of offshore saline intrusions during the summer would weaken the correlation between seasonal river discharge and shelf salinity. Therefore, despite the 
lag observed between river discharge and shelf salinity, it is not unreasonable that we observed the strongest anticorrelation between Winter/Spring discharge and Winter/Spring shelf salinity (Fig. 5).

\section{b. Decadal-scale variability in the Mid-Atlantic Bight}

$i$. Temperature. We expected that water temperatures would continue to rise with a warming climate. Across MAB regions and northwards into GB and the GOM, trends in temperature observed during the last decade (1999-2016) and during the period of Mountain's (2003) study (1977-1999) followed this pattern. Only the first period (1977-1999), however, shows many regions with significant warming. Indeed, some of the southern MAB showed rising trends in temperature in the first period near $1{ }^{\circ} \mathrm{C} /$ decade. Although the general warming trends observed during the last decade and half (1999-2016) seem to be a continuation of the warming trend from the earlier period (1977-1999) for nearly all the regions, most of the trends are not statistically significant when evaluated over just the second period.

Forsyth et al. (2015) also studied decadal changes in temperature along the MAB using XBT data from the CMV Oleander that travels between New Jersey and Bermuda. They observed small magnitude warming trends across the MAB in the last decade (2002-2013) with $0.086{ }^{\circ} \mathrm{C} /$ decade in the Winter/Spring, $0.19{ }^{\circ} \mathrm{C} / \mathrm{decade}$ in the Summer, and 0.095 ${ }^{\circ} \mathrm{C} /$ decade in the Fall. Our results for the NYB1 region, which spatially overlaps with Forsyth and colleagues' dataset, showed insignificant warming or cooling during a similar timespan. However, over the whole 40 years, we found significantly higher warming rates of $0.45{ }^{\circ} \mathrm{C} / \mathrm{decade}$ for Winter/Spring and $0.39{ }^{\circ} \mathrm{C} /$ decade for Fall/Winter in NYB1. Forsyth et al. (2015) noted that by changing the time period characterized to 2004-2012, the reported temperature trend increased by a factor of two. This sensitivity points to the inherent ambiguity of quantifying temporal trends in short time series that have strong interannual variability. Our statistically significant trends over the 40 -year period are objectively less skewed by interannual variabilities.

By looking at the changing locations and timing of significant trends in both periods, we can observe a shift in the spatial pattern of warming (Fig. 9). During the first period (1977-1999), the southern regions of the MAB showed the largest significant temperature increase, exceeding $1{ }^{\circ} \mathrm{C} /$ decade during the Winter/Spring season (Fig. 7). During the second period (1999-2016), however, there was no significant warming or cooling observed in Winter/Spring or Summer seasons; all significant warming of shelf water was observed during the Fall/Winter season in the northern MAB regions. The cause of the shift in the location and season of warming in the MAB on the decadal time scale will be the topic of a future investigation.

ii. Salinity. Unlike the temperature trends discussed above that showed warming in both periods, the salinity trend in regions across the MAB and north of the MAB changed 
dramatically from the first study period (1977-1999) to the second study period (19992016). In the first period, we observed significant freshening trends in various regions, most predominantly in the Winter/Spring and Summer seasons (Fig. 7d-f). However, the second period showed significant salting trends during the Fall/Winter season in the northern MAB (Fig. 8d-f). Within our study period of 40 years, the MAB shelf switched from a freshening mode from 1977 to 1999 to a salting mode from 1999 to 2016. In sum, there was no net salinity change over the 40 year period.

The increased freshening from 1977-1999, especially for shelf water during Winter/Spring, indicates that there was an influx of freshwater into the shelf. It is possible that the significant freshening trends in some regions of the MAB observed from 19771999 are a result of increased river discharge. Most of the significant freshening trends observed in the Summer occurred most prominently in the NYB and SS2 regions that are also located offshore of the Hudson River and Chesapeake Bay basin, respectively. Comparing the monthly average discharge in the first period to the discharge in the second period for Chesapeake Bay shows no significant differences for any month (Fig. 15). For the Hudson River, there are no significant differences in river discharge between the two periods except during the Summer months (June, July, August) when discharge was greater in the second period (Fig. 15). Therefore, we can rule out an increase in the river discharge as the main contributor to the change from the freshening trends we observed in the first period to the salting trends in the second period.

Another possible contributor to the increased freshening in the first period for both the $\mathrm{MAB}$ and upstream of the MAB could be increased advection of fresher water from the Scotian shelf. Mountain (1991) found that interannual changes in the volume of shelf water seem to be associated with changes in the inflow of water into the GOM (Mountain 1991). Supposing that such an influx of freshwater was entering the MAB, given the along-shelf advection time scale of 3-4 months, the southern regions would see the largest decrease in salinity later in the Summer season, which is observed in our data (i.e., Fig. 9).

Several low salinity events known as the Great Salinity Anomalies (GSA) were observed in the 1990s (Belkin 2004; Belkin et al. 1998; Drinkwater 1996). Station 27 off the coast of St. Johns, Newfoundland indicated increased ice coverage and a minimum in salinity in both 1991 and 1995 (Drinkwater 1996). Although the effects of the GSAs were only tracked in the Northern Atlantic by Belkin et al. (1998) and Belkin (2004), our data indicate that the effects of the GSA in the 1990s might have stretched as far as the southern MAB (Belkin 2004; Belkin et al. 1998). In addition, Smith et al. (2001) observed increased inflow of low salinity water into the GOM at surface in the late 1990s. No indication of another GSA has been detected since 1996. Consistent with these observations, salinity has risen to its regular levels during the second period of study (1999-2016) across the MAB.

Another possible physical factor driving shelf salinity change is the contribution of intrusions of offshore water onto the shelf. Collectively, the temperature and salinity profile analyses suggest that there might have been decadal scale change in the frequency and extent of slope and/or Gulf Stream water intrusions onto the MAB shelf with warmer and 

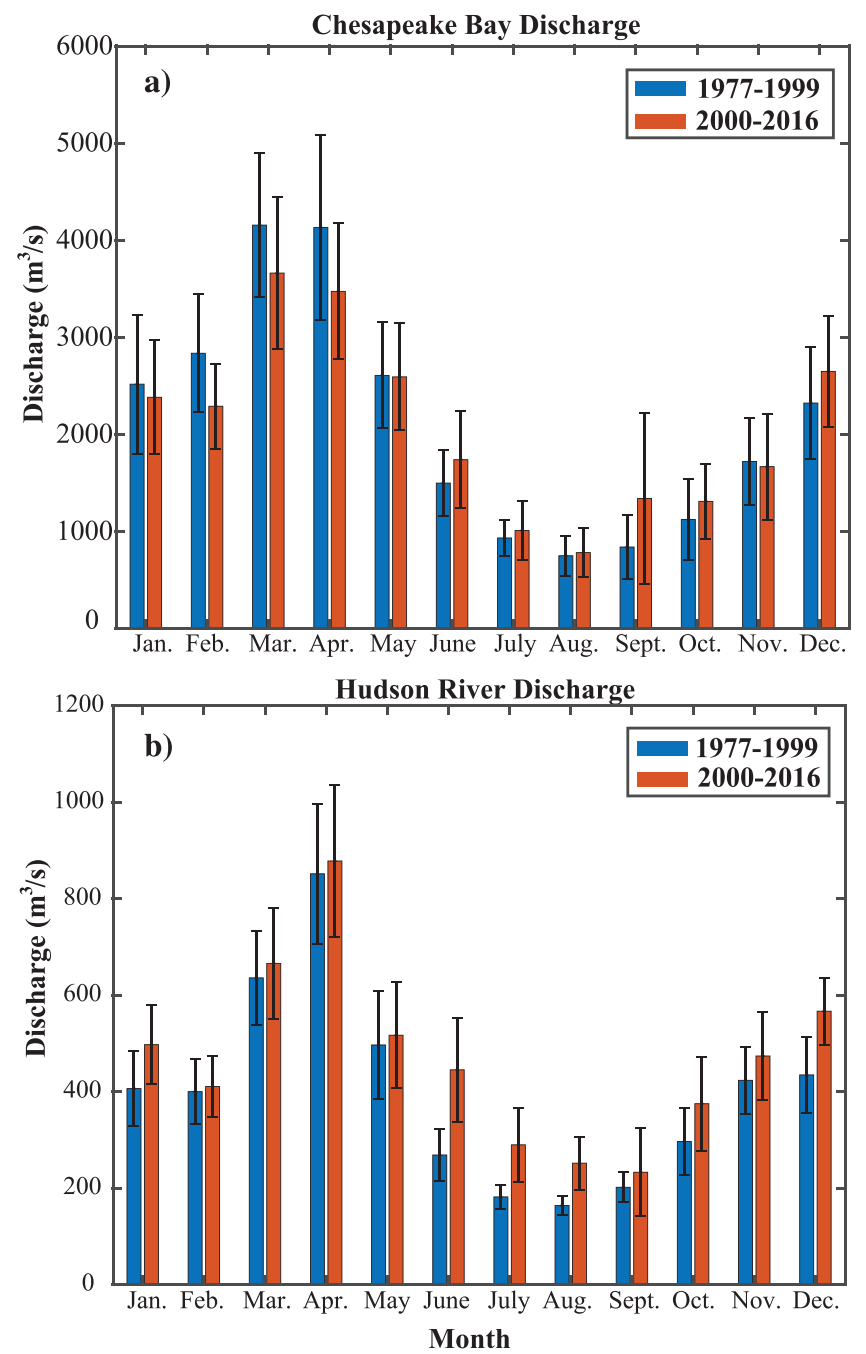

Figure 15. Comparison of average monthly discharge from the Hudson River (a) and the Chesapeake Bay (b) from 1977-1999 (blue) and 1999-2016 (orange). Error bars are shown in black.

saltier water at depth in many regions during the second period. Indeed, recent studies have observed a shift in the Gulf Stream destabilization point to the west bringing the meandering Gulf Stream closer to the MAB shelf and its equatorward currents (Andres 2016). With a closer meandering Gulf Stream, there would be an increased influence of the Gulf Stream on the MAB shelf that could lead to increased salinity throughout the water column on the outer MAB shelf. These events include extreme Gulf Stream diversions and pinched off Gulf Stream rings that flood the MAB slope with warm, salty water (Gawarkiewicz 
et al. 2012). Our analysis of water mass properties in the MAB suggests that these observed changes in the Gulf Stream meander position may be causing increased saline intrusions on the MAB shelves in the recent decades. However, a separate study dedicated to exploring the dynamical relationship between the Gulf Stream and intrusions in the MAB is needed to properly characterize these connections.

\section{Conclusions}

This analysis of hydrographic survey data along the MAB, GOM, and GB revealed significant decadal variation in temperature and salinity.

1. From 1977 to 2016 , the MAB water column experienced approximately $0.5^{\circ} \mathrm{C}$ per decade of warming. This warming was most prominent in the northernmost regions of the MAB and from September through April. The GOM and GB warmed at approximately half the rate the MAB over the same time span (1977-2016). The observed long-term temperature change is consistent with being driven by atmospheric warming. However, dominant warming observed during the winter season suggests that along-shore advection and offshore heat flux make a nontrivial impact on the variability of the seasonal trends.

2. There was negligible change in salinity from 1977-2016 in the GOM, GB, and MAB.

3. Significant temperature increase trends $\left(>0.6^{\circ} \mathrm{C} /\right.$ decade $)$ were observed in many of the southern regions of the MAB in the Winter/Spring season from 1977 to 1999. The warming trends for much of the MAB from 1999 to 2016 are not significant given the smaller size of the dataset for this time period.

4. Significant freshening trends ( $>-0.2 /$ decade) were observed in many regions of the MAB in the Winter/Spring and Summer seasons from 1977-1999. For 1999 to 2016, most regions experienced no significant changes in salinity, but some northern MAB regions showed significant salting.

5. Analyses of interannual variability of seasonal shelf salinity and seasonal river discharge indicated a significant anticorrelation relationship during the Winter/Spring season. This suggests that increased river input into the shelf regions contributes significantly to freshening on the shelf on yearly basis. However, comparison of discharge from the first period to the second period suggest that river discharge is not the main contributor of changing shelf salinity trends from the first period to the second period.

6. High salinity values were observed at depths of midwater column and bottom intrusions from 1999-2016 in the mid-MAB regions suggesting that saline intrusions from offshore is a significant contributor to higher shelf salinities. This trend may correspond to observed changes in the Gulf Stream meander position in the recent decade.

This analysis aimed to characterize the MAB temperature and salinity over the last 40 years. The trends observed were found to be influenced by local and potentially remote 
forcing factors. Statistically significant warming trends for the MAB, GB, and GOM were attributed mainly to atmospheric warming with contribution from along-shelf advection. Interannual salinity variability observed in the $\mathrm{MAB}$ were linked to local river discharge, and changes in long-term salinity trends seem to be driven by an increase in offshore salt supply. However, it is beyond the scope of this work to fully account for the MAB shelf salinity budget. A future analysis using a fully-validated data assimilative numerical model or reanalysis is needed. It is hoped that this paper will motivate future dynamical investigations into the various forcing factors driving temperature and salinity variability in the MAB, GB, and GOM.

Acknowledgments. The dataset for this paper is available at NOAA's Northeast Fisheries Science Center Oceanography Branch (http://www.nefsc.noaa.gov/epd/ocean/MainPage/ioos.html). Dataset name: Water Column Properties (CTD/profile data). This research was supported by the Research Experience for Undergraduates program at the Virginia Institute for Marine Science and the National Science Foundation Grant \# OCE0552612. We would like to thank P. Frantantoni for her efforts in the collection and quality control of the dataset and E. Curchitser for his help in understanding and using SODA data. We also want to thank C. Friedrichs, R. Rykaczewski, S. Lentz, and G. Gawarkiewicz for their insightful comments on earlier drafts of this manuscript.

\section{APPENDIX A}

\section{Comparison of temperature and salinity variability with Simple Ocean Data Assimilation estimates}

The Simple Ocean Data Assimilation (SODA) model (Version 3.4.2) is an ocean reanalysis product based on the Modular Ocean Model v5 ocean component of National Oceanic and Atmospheric Administration (NOAA) Geophysical Fluid Dynamics CM2.5 coupled model (Carton et al. 2018). The output has a horizontal resolution of $0.25^{\circ} \times 0.25^{\circ}$ with 40 vertical levels and a monthly temporal resolution from 1980 to 2015 . Its observations include hydrographic profile and ocean station data and moored temperature and salinity data, as well as nighttime satellite SST data.

Comparison between the conductivity-temperature-depth (CTD) data and the SODA reanalysis was done for all the seasons and all the regions using the exact same data processing pipeline. Figures A8-A16 show time series comparisons for temperature (left panels) and salinity (right panels) for each season from 1980 to 2015. The correlations are printed in the title for each figure. For the Mid-Atlantic Bight (MAB), the correlation, R, for both temperature and salinity are highest in the Winter/Spring season ( $R=0.91-0.93)$. The lowest correlation was found during the stratified summer season for temperature with $R=0.45$, whereas the correlations for other seasons were between $R=0.8-0.86$. For the Gulf of Maine (GOM), the correlations were high $(R>0.92)$ for both temperature and salinity and for all seasons. For GB, the temperature correlations were between $R=0.82-0.87$, and the salinity correlations were between $R=0.67-0.72$. There was no strong seasonal dependence for Georges Bank (GB). 
Within the subregions of the MAB, the correlations were highest in the northern regions (Southern New England (SNE) and New York Bight 1 (NYB1)) and lowest in the southern regions (Southern Shelf 1 (SS1) and Southern Shelf 2 (SS2)). Although for the Winter/Spring season, both temperature and salinity correlations remain high $(R=0.76-0.8)$, the correlations break down for the stratified Summer and Fall/Winter seasons $(\mathrm{R}<0.5)$. Overall, there was high correlation between CTD data and SODA reanalysis in the colder less stratified regimes. This result indicates that SODA may be useful for future heat and salt budget analyses in the MAB, GB, and GOM under specific conditions. 


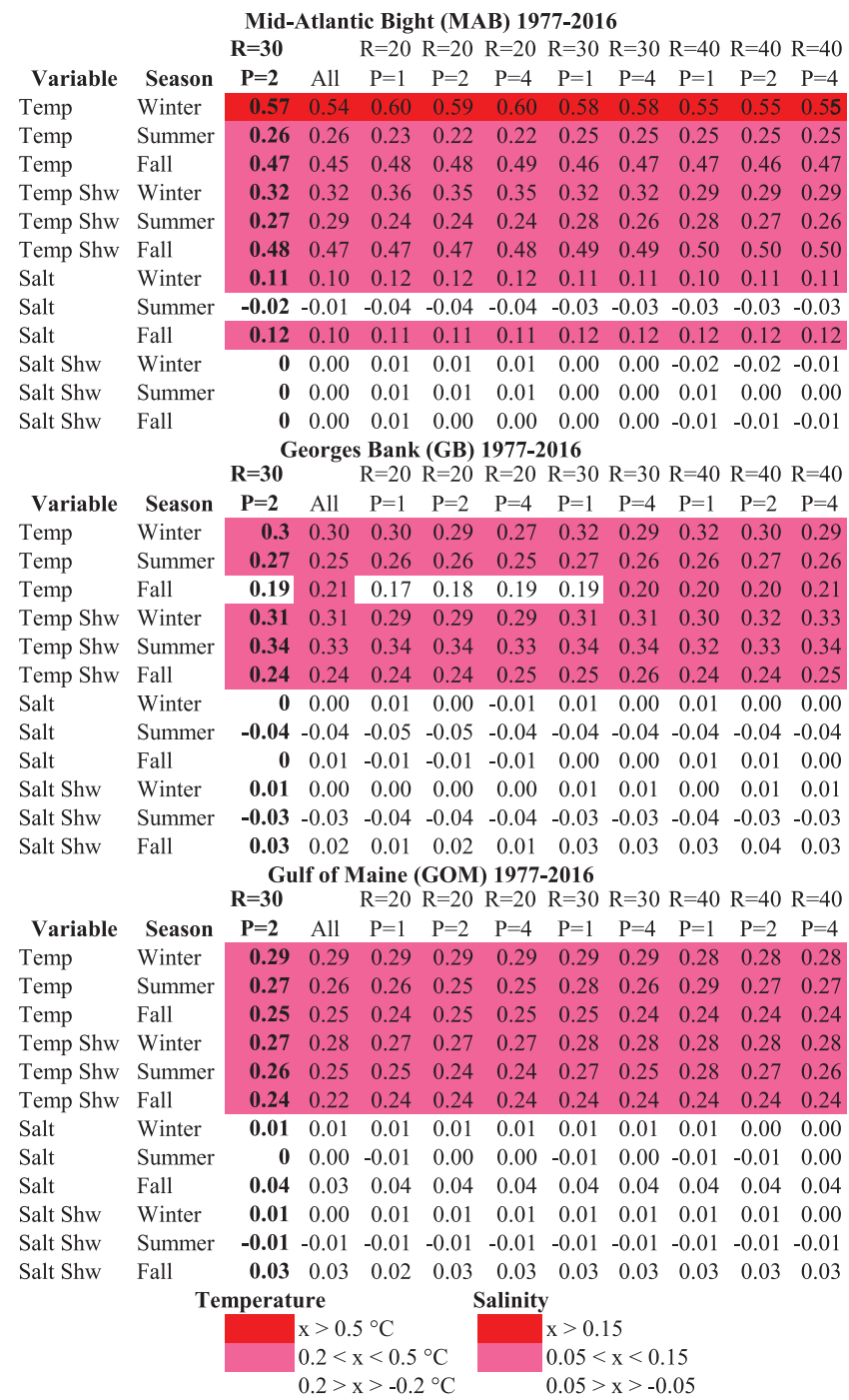

Figure A1. Sensitivity to values of $P$ and $R$ in Eq. 2. The rates of change in temperature and salinity for all water masses and shelf water only for values of $P=1,2$, and 4 and $R=20 \mathrm{~km}, 35 \mathrm{~km}$, and $40 \mathrm{~km}$. The values for each season in the Mid-Atlantic Bight (MAB), Georges Bank (GB) and Gulf of Maine (GOM) from 1977-2016 are shown. The rates (per decade) are the slope of the linear fits to the temperature and salinity time series for each region and season. The bolded first column shows the results used in this study with $R=30 \mathrm{~km}$ and $P=2$. The composite column is the average result for all the different $R$ and $P$ values. There is practically no difference between the composite values and the values we calculated using $R=30 \mathrm{~km}$ and $P=2$. The boxes are color coded to denote the scale of the change in slope and facilitate comparison between time periods with red indicating a large increase, pink a small increase, and white negligible change. 

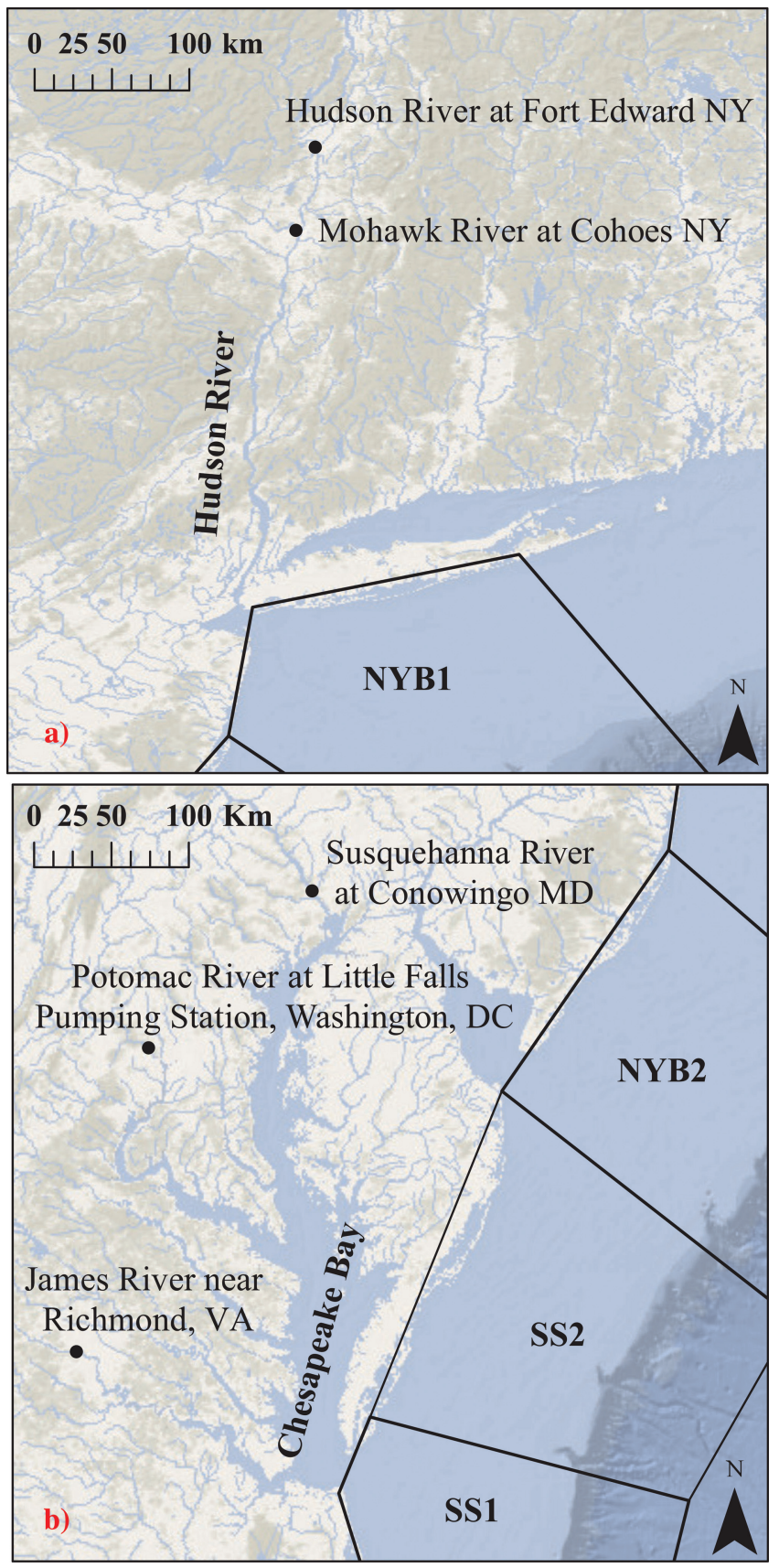

Figure A2. Maps showing the locations of the U.S. Geological Survey (USGS) river gage stations used in calculation of river discharge for the Hudson River (a) and Chesapeake Bay (b). 
Summer (1977-2016)
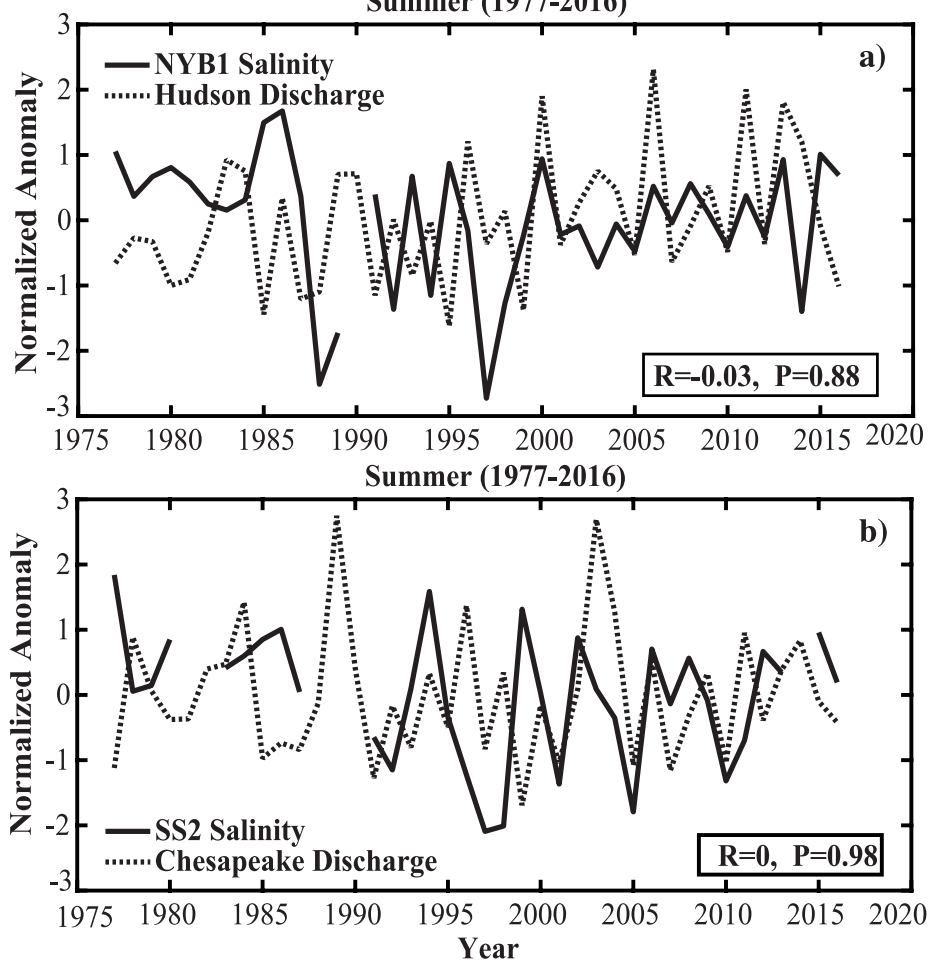

Figure A3. Plots of the standardized anomaly of seasonally averaged shelf salinity and seasonally integrated freshwater transport as functions of time in (a) the New York Bight 1 (NYB1) and (b) Southern Shelf 2 (SS2) regions for the Summer season from 1977 to 2016. Hudson River discharge is compared with salinity in the NYB1 region and net Chesapeake Bay discharge is compared with salinity in the SS2 region. The correlation for NYB1 and the Hudson River discharge is $R=-0.03$ and correlation for SS2 and the Chesapeake Bay discharge is $R=0$. Both correlations are NOT significant at the $95 \%$ confidence level. 

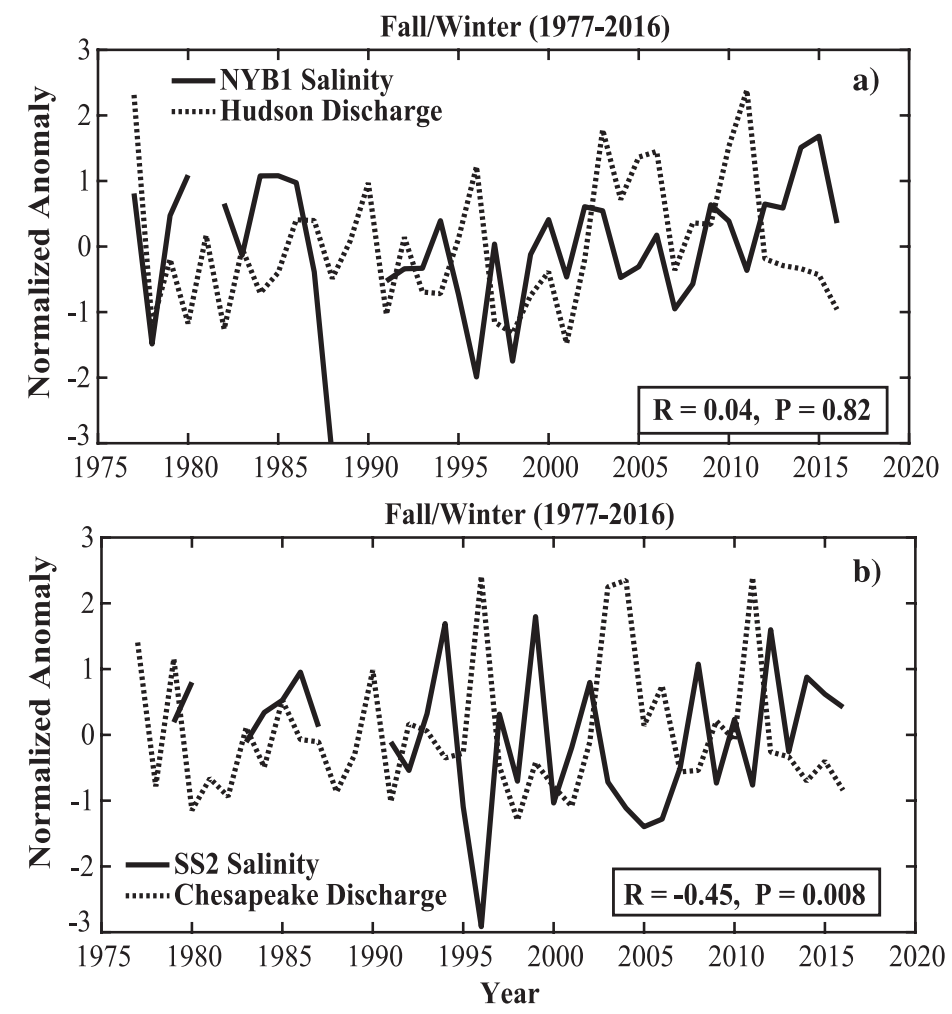

Figure A4. Plots of the standardized anomaly of seasonally averaged shelf salinity and seasonally integrated freshwater transport as functions of time in (a) the New York Bight 1 (NYB1) and (b) Southern Shelf 2 (SS2) regions for the Fall/Winter season from 1977 to 2016. Hudson River discharge is compared with salinity in the NYB1 region and net Chesapeake Bay discharge is compared with salinity in the SS2 region. The correlation for NYB1 and the Hudson River discharge is $R=-0.004$ and correlation for SS2 and the Chesapeake Bay discharge is $R=-0.45$. Only the correlation between SS2 and the Chesapeake Bay discharge is significant at the $95 \%$ confidence level. 

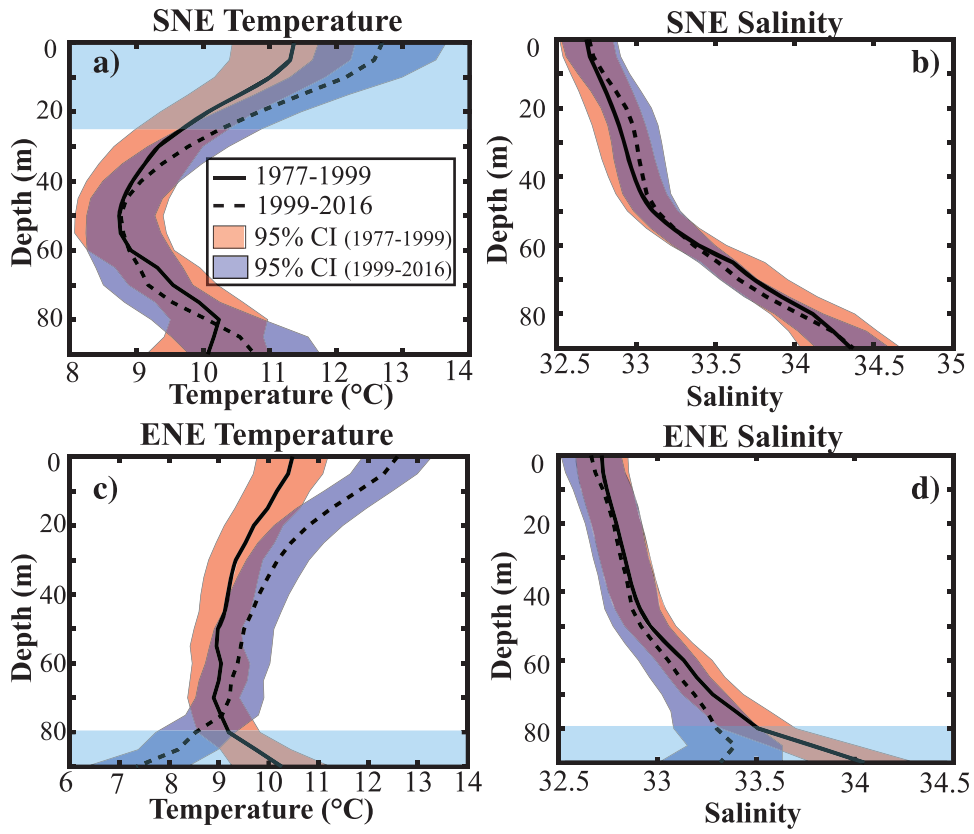

Figure A5. Profiles of salinity and temperature (stations extending from at least $50 \mathrm{~m}$ to $90 \mathrm{~m}$ in depth) in the Southern New England (SNE) (a, b) and Eastern New England (ENE) (c, d) from 1977-1999 (solid line) and from 1999-2016 (dashed line). The 95\% confidence intervals around each profile are shown in red and blue for the first and second period, respectively. Blue horizontal bars highlight the water depths with important significant differences between the first and second period. 


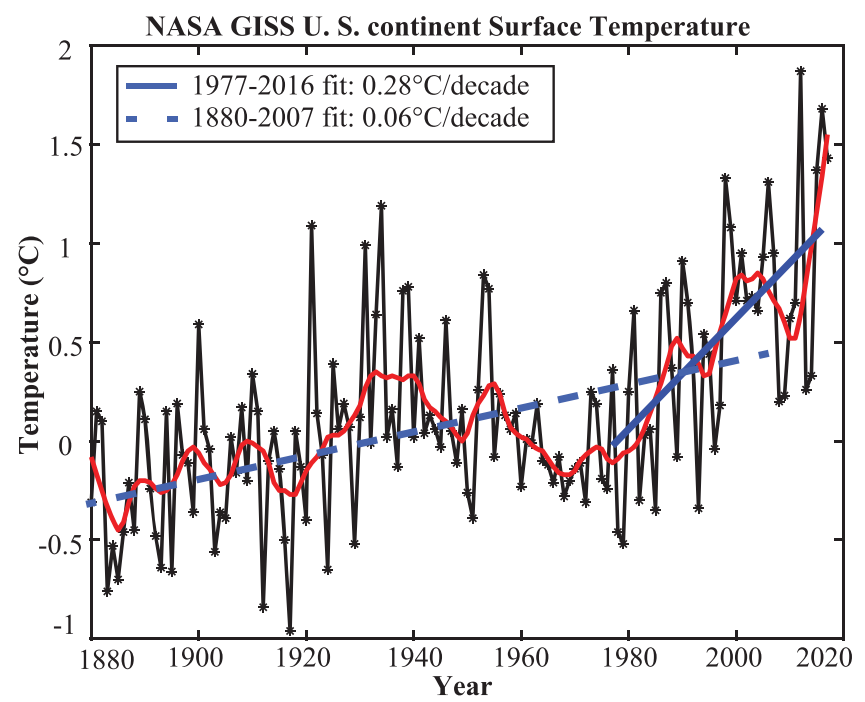

Figure A6. US continent annual surface temperature (black) from 1880-2016 from NASA GISS data. A five-year lowess smoother (red) was applied to the data. The linear fit from 1880-2007 (dashed blue) and from 1977-2016 (blue solid) are plotted. 

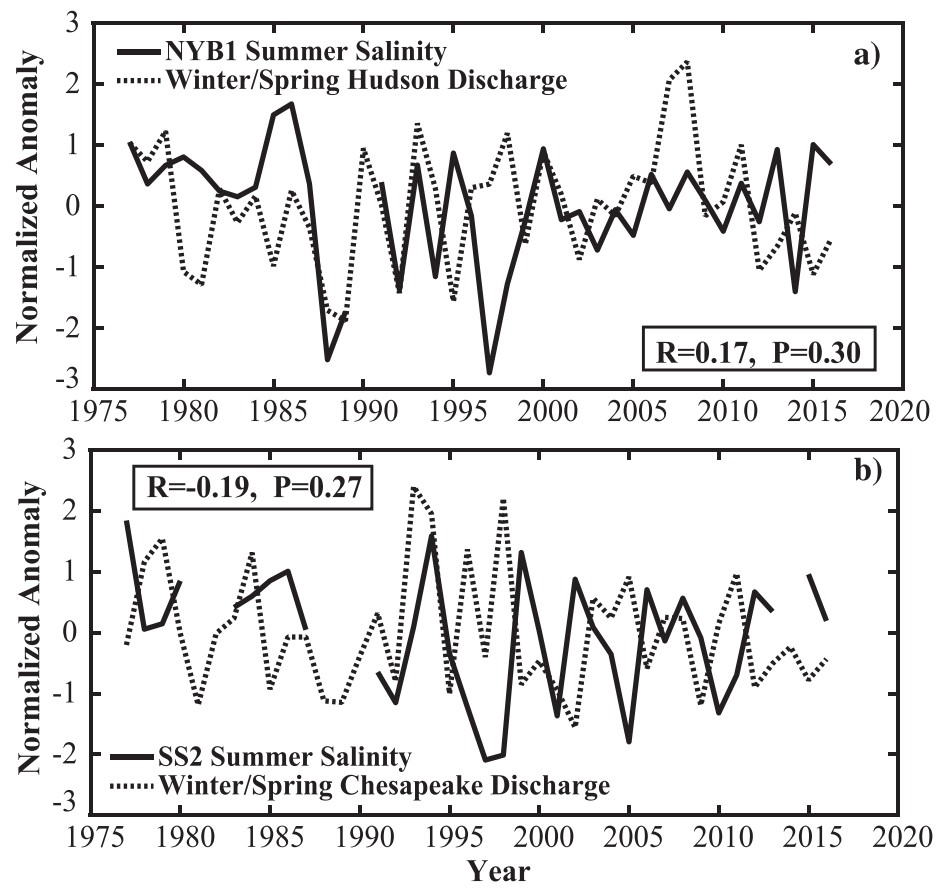

Figure A7. Plots of the standardized anomaly of seasonally averaged Summer shelf salinity and seasonally integrated Winter/Spring freshwater transport as functions of time in (a) the New York Bight 1 (NYB1) and (b) Southern Shelf 2 (SS2) regions from 1977 to 2016 . Hudson River discharge is compared with salinity in the NYB1 region and net Chesapeake Bay discharge is compared with salinity in the SS2 region. The correlation for NYB1 and the Hudson River discharge is $R=0.17$ and correlation for SS2 and the Chesapeake Bay discharge is $R=-0.19$. Both correlations are NOT significant at the $95 \%$ confidence level. 
a) GOM Winter/Spring ( $R=0.92)$ d) GOM Winter/Spring $(\mathrm{R}=0.96)$
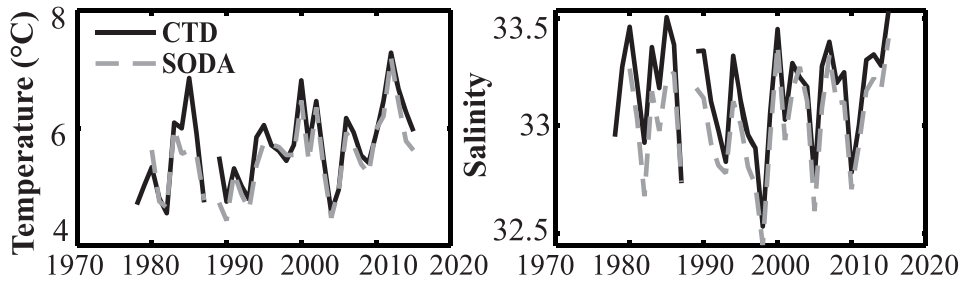

b) GOM Summer $(\mathrm{R}=\mathbf{0 . 9 2})$

e) GOM Summer $(\mathrm{R}=\mathbf{0 . 9 5})$
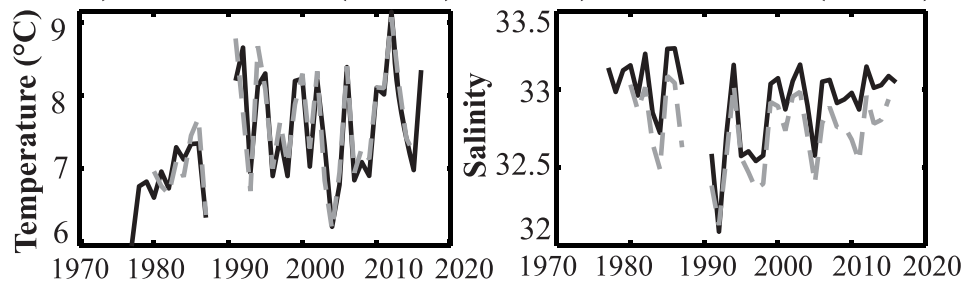

c) GOM Fall/Winter $(\mathrm{R}=\mathbf{0 . 9 7})$

f) GOM Fall/Winter $(\mathrm{R}=0.92)$
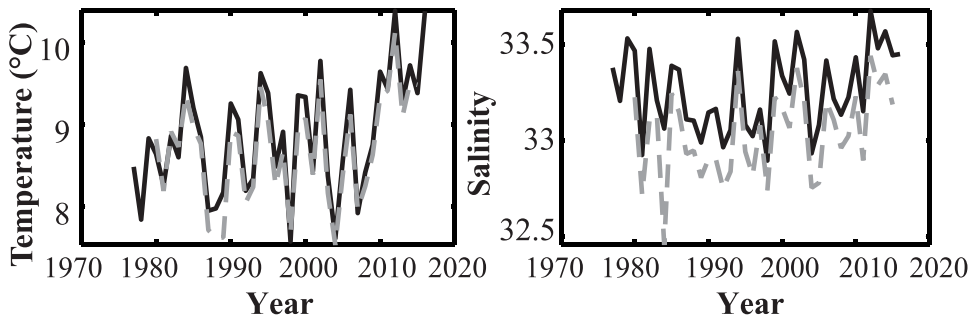

Figure A8. Plots of temperature (a-c) and salinity (d-f) for each season in the Gulf of Maine (GOM) region created with Simple Ocean Data Assimilation (SODA) model output (Version 3.4.2) from 1977 to 2016 (dashed line) and Northeast Fisheries Science Center (NEFSC) station data (solid line). Both datasets were sampled and processed using the same methodology. The titles of each subplot show the rho from correlation analyses between the two datasets (dashed and solid lines). 
a) GB Winter/Spring $(\mathrm{R}=\mathbf{0 . 8 7})$

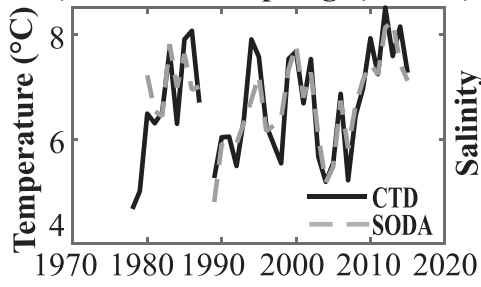

d) GB Winter/Spring $(\mathrm{R}=\mathbf{0 . 7})$
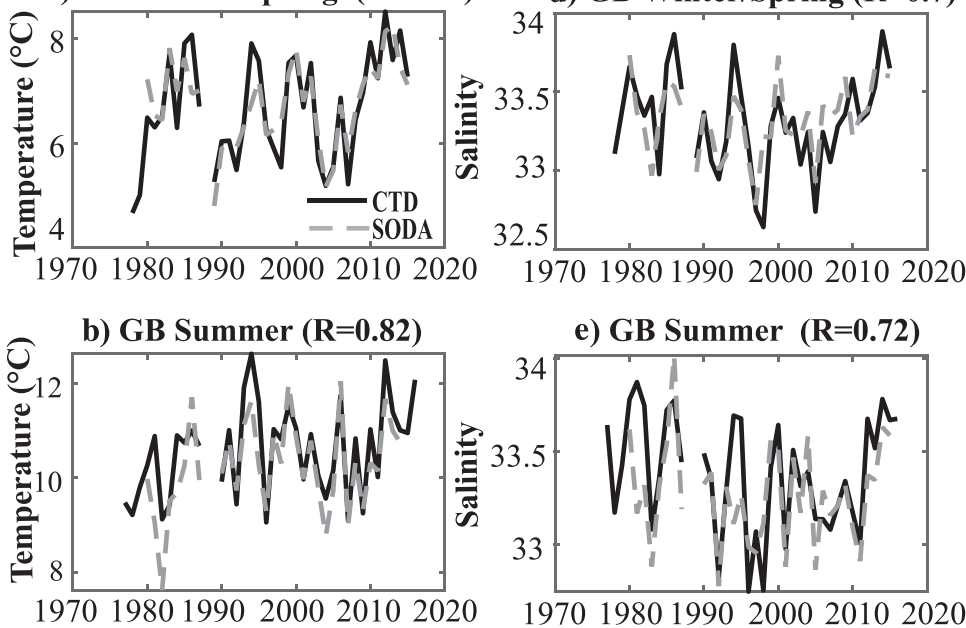

e) GB Summer $(\mathbf{R}=\mathbf{0 . 7 2})$

c) GB Fall/Winter $(R=0.83)$
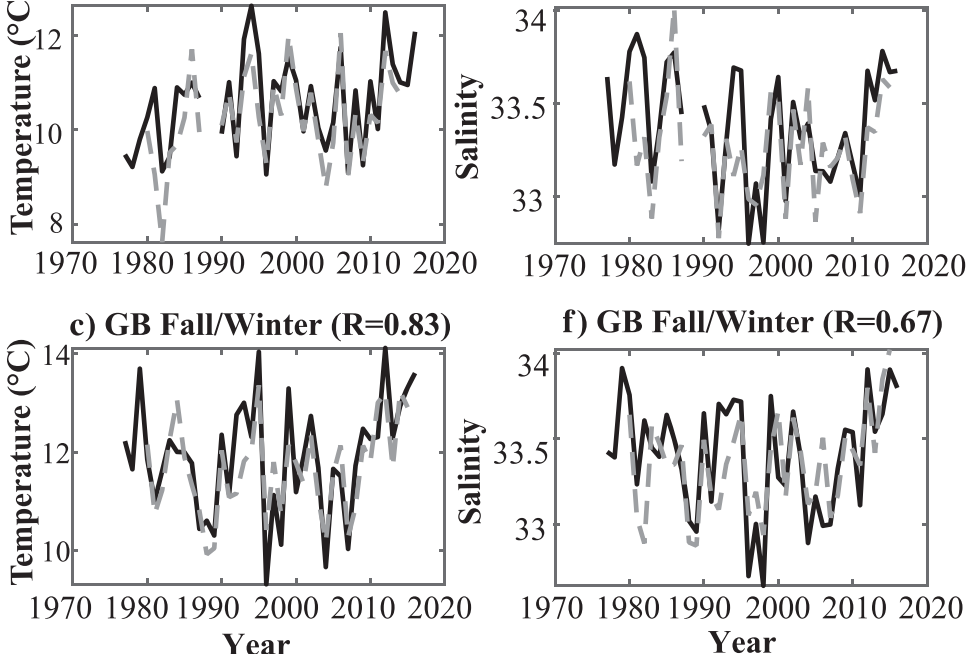

f) GB Fall/Winter $(\mathrm{R}=\mathbf{0 . 6 7})$

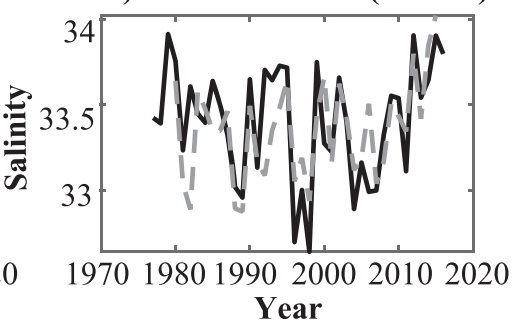

Figure A9. Plots of temperature (a-c) and salinity $(\mathrm{d}-\mathrm{f})$ for each season in the Georges Bank (GB) region created with Simple Ocean Data Assimilation (SODA) model output (Version 3.4.2) from 1977 to 2016 (dashed line) and Northeast Fisheries Science Center (NEFSC) station data (solid line). Both datasets were sampled and processed using the same methodology. The titles of each subplot show the rho from correlation analyses between the two datasets (dashed and solid lines). 
a) ENE Winter/Spring $(\mathrm{R}=\mathbf{0 . 8 2})$

d) ENE Winter/Spring $(\mathrm{R}=\mathbf{0 . 6 9})$
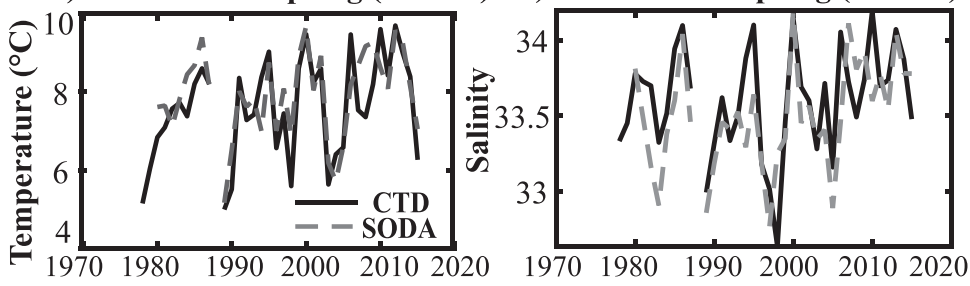

b) ENE Summer $(R=0.75)$

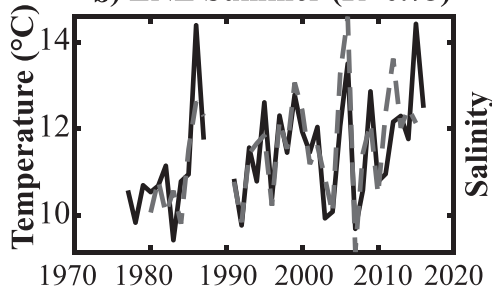

e) ENE Summer $(R=0.79)$

c) ENE Fall/Winter $(\mathrm{R}=0.8)$
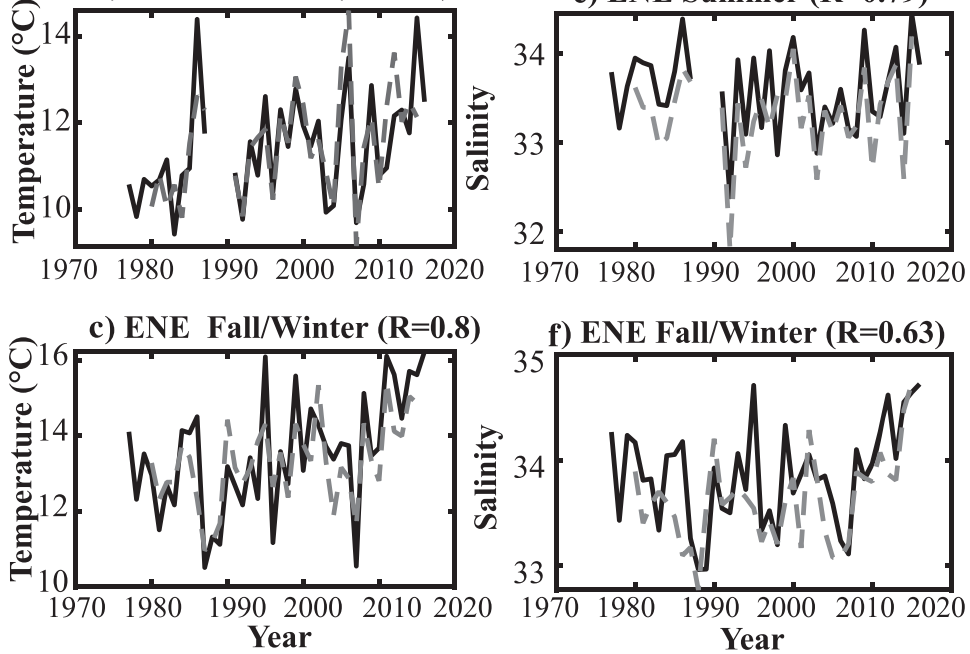

Figure A10. Plots of temperature (a-c) and salinity $(\mathrm{d}-\mathrm{f})$ for each season in the Eastern New England (ENE) region created with Simple Ocean Data Assimilation (SODA) model output (Version 3.4.2) from 1977 to 2016 (dashed line) and Northeast Fisheries Science Center (NEFSC) station data (solid line). Both datasets were sampled and processed using the same methodology. The titles of each subplot show the rho from correlation analyses between the two datasets (dashed and solid lines). 
a) MAB Winter/Spring $(\mathrm{R}=\mathbf{0 . 9 3})$

d) MAB Winter/Spring $(\mathbf{R}=\mathbf{0 . 9 1})$
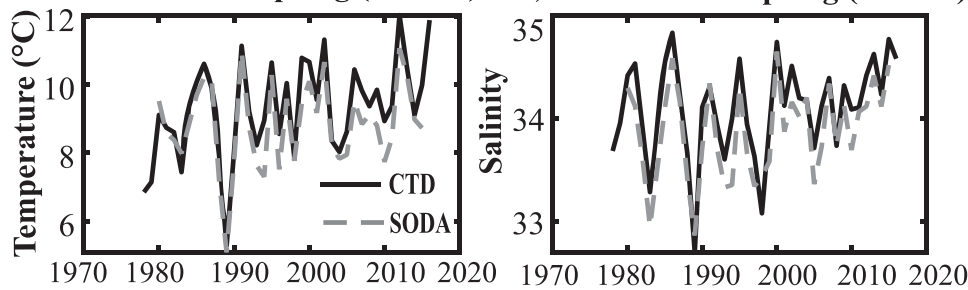

b) MAB Summer $(R=0.45)$

e) MAB Summer $(\mathbf{R}=\mathbf{0 . 8 6})$
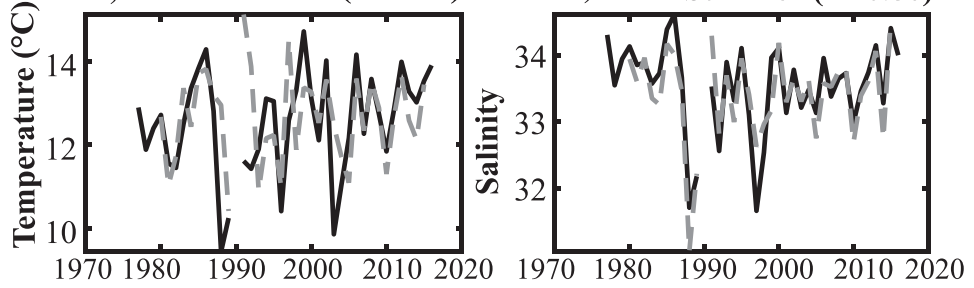

c) $M A B$ Fall/Winter $(R=0.8)$

f) $\mathrm{MAB}$ Fall/Winter $(\mathrm{R}=\mathbf{0 . 8 2})$
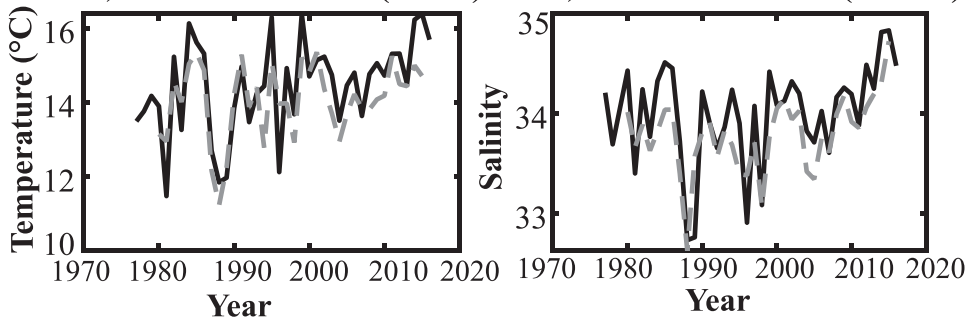

Figure A11. Plots of temperature $(\mathrm{a}-\mathrm{c})$ and salinity $(\mathrm{d}-\mathrm{f})$ for each season in the Mid-Atlantic Bight (MAB) region created with Simple Ocean Data Assimilation (SODA) model output (Version 3.4.2) from 1977 to 2016 (dashed line) and Northeast Fisheries Science Center (NEFSC) station data (solid line). Both datasets were sampled and processed using the same methodology. The titles of each subplot show the rho from correlation analyses between the two datasets (dashed and solid lines). 
a) SNE Winter/Spring $(\mathrm{R}=\mathbf{0 . 8 6})$

d) SNE Winter/Spring $(\mathrm{R}=\mathbf{0 . 8 2})$
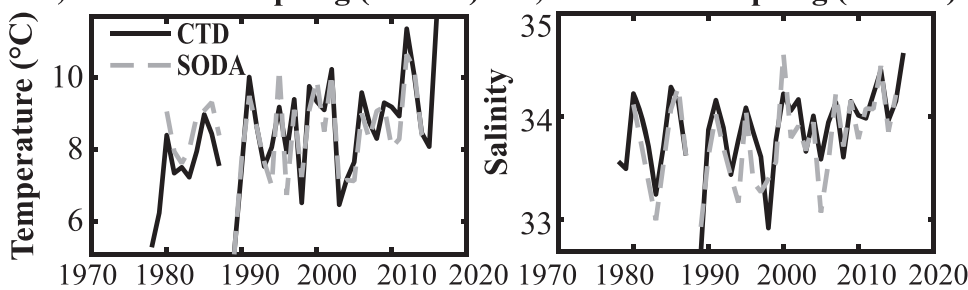

b) SNE Summer $(\mathrm{R}=\mathbf{0 . 7 6})$

e) $\mathrm{SNE}$ Summer $(\mathrm{R}=\mathbf{0 . 8 9})$
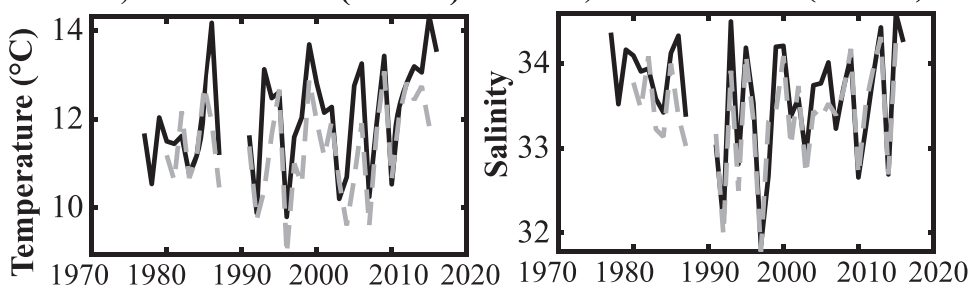

c) SNE Fall/Winter $(\mathrm{R}=\mathbf{0 . 7 8})$

f) $\mathrm{SNE}$ Fall/Winter $(\mathrm{R}=\mathbf{0 . 7 8})$
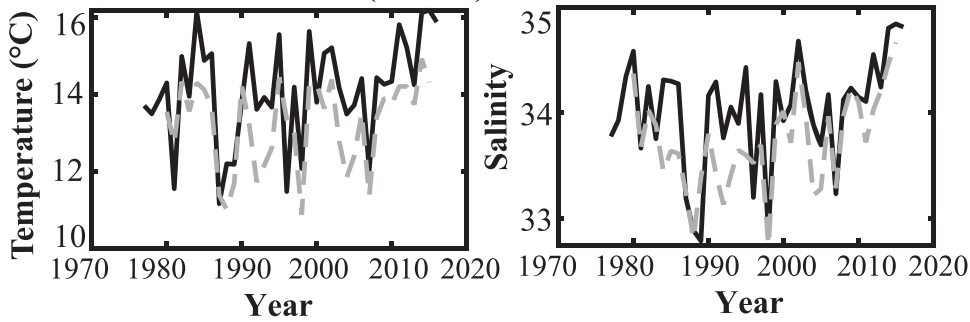

Figure A12. Plots of temperature (a-c) and salinity (d-f) for each season in the Southern New England (SNE) region created with Simple Ocean Data Assimilation (SODA) model output (Version 3.4.2) from 1977 to 2016 (dashed line) and Northeast Fisheries Science Center (NEFSC) station data (solid line). Both datasets were sampled and processed using the same methodology. The titles of each subplot show the rho from correlation analyses between the two datasets (dashed and solid lines). 
a) NYB1 Winter/Spring $(\mathrm{R}=\mathbf{0 . 8 9})$

d) NYB1 Winter/Spring $(\mathbf{R}=\mathbf{0 . 8 9})$
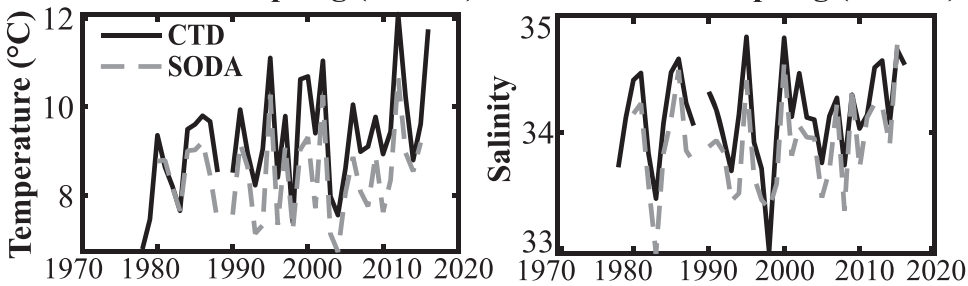

b) NYB1 Summer $(R=0.58)$

e) NYB1 Summer $(\mathrm{R}=\mathbf{0 . 9 2})$
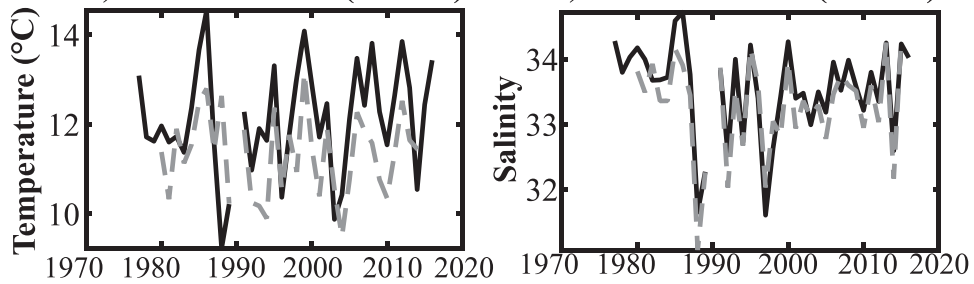

c) NYB1 Fall/Winter $(\mathrm{R}=\mathbf{0 . 7 5})$

f) NYB1 Fall/Winter $(\mathrm{R}=\mathbf{0 . 8 7})$
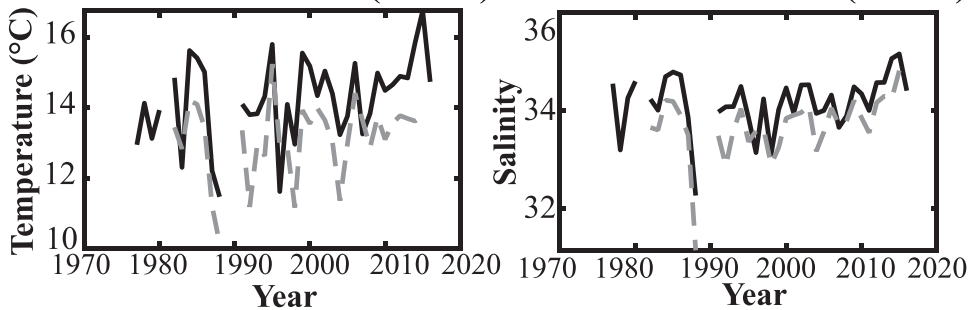

Figure A13. Plots of temperature $(a-c)$ and salinity $(d-f)$ for each season in the New York Bight 1 (NYB1) region created with Simple Ocean Data Assimilation (SODA) model output (Version 3.4.2) from 1977 to 2016 (dashed line) and Northeast Fisheries Science Center (NEFSC) station data (solid line). Both datasets were sampled and processed using the same methodology. The titles of each subplot show the rho from correlation analyses between the two datasets (dashed and solid lines). 


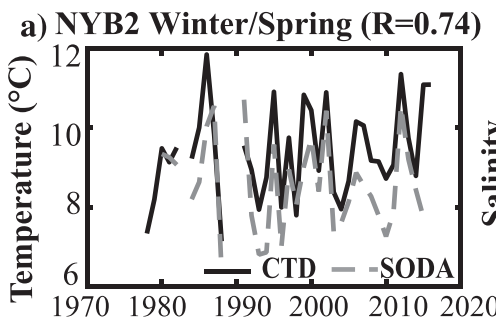

d) NYB2 Winter/Spring $(\mathrm{R}=\mathbf{0 . 8 3})$

b) NYB2 Summer $(R=0.39)$
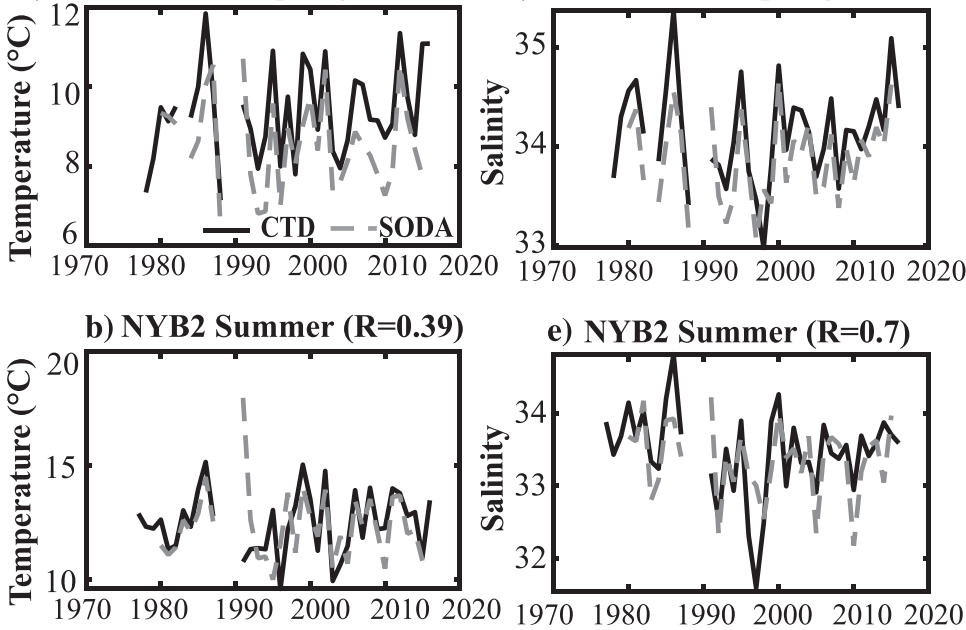

e) NYB2 Summer $(R=0.7)$

c) NYB2 Fall/Winter $(\mathrm{R}=0.41)$
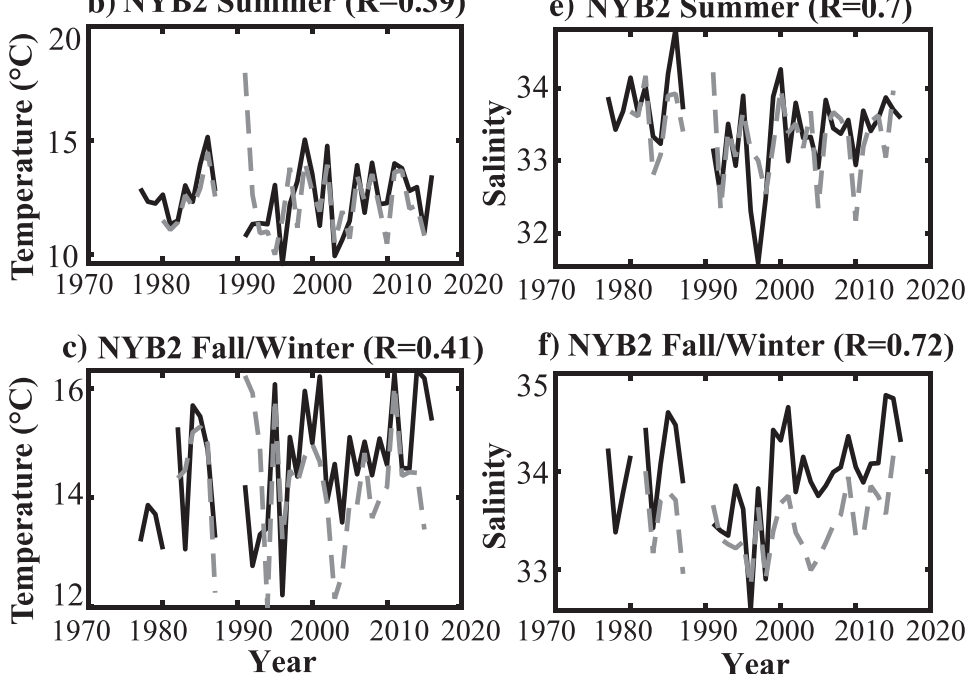

f) NYB2 Fall/Winter $(\mathrm{R}=\mathbf{0 . 7 2})$

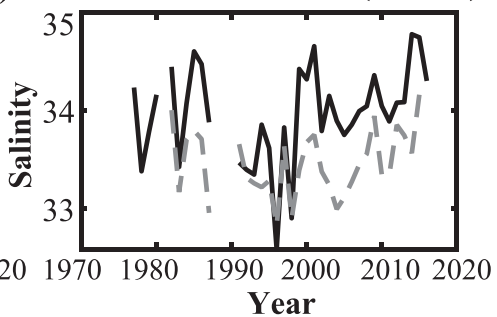

Figure A14. Plots of temperature $(\mathrm{a}-\mathrm{c})$ and salinity $(\mathrm{d}-\mathrm{f})$ for each season in the New York Bight 2 (NYB2) region created with Simple Ocean Data Assimilation (SODA) model output (Version 3.4.2) from 1977 to 2016 (dashed line) and Northeast Fisheries Science Center (NEFSC) station data (solid line). Both datasets were sampled and processed using the same methodology. The titles of each subplot show the rho from correlation analyses between the two datasets (dashed and solid lines). 
a) SS1 Winter/Spring $(\mathbf{R}=\mathbf{0 . 7 9})$

b) SS1 Winter/Spring $(\mathrm{R}=\mathbf{0 . 7 6})$
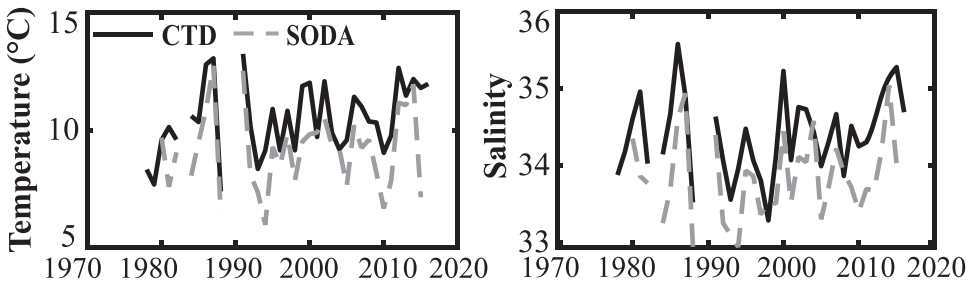

b) SS1 Summer $(\mathbf{R}=\mathbf{0 . 0 8})$

e) SS1 Summer $(\mathrm{R}=\mathbf{0 . 5 8})$
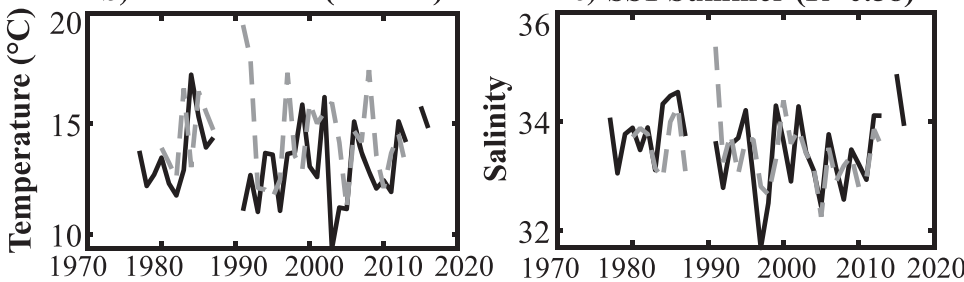

c) $\mathrm{SS1}$ Fall/Winter $(\mathrm{R}=\mathbf{0 . 0 6})$
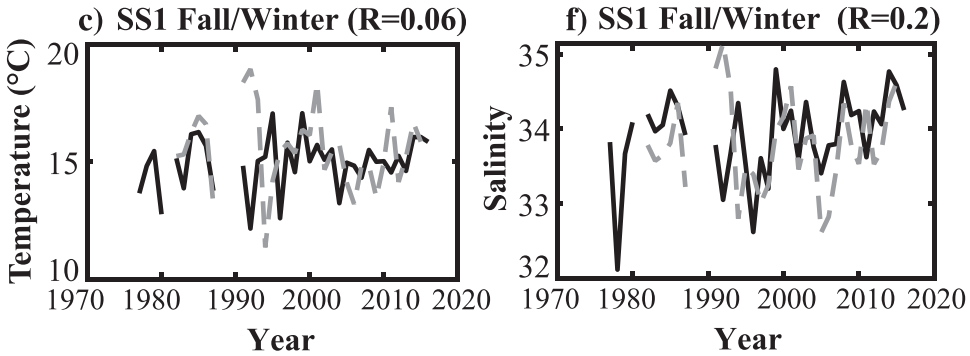

Figure A15. Plots of temperature $(a-c)$ and salinity $(d-f)$ for each season in the Southern Shelf 1 (SS1) region created with Simple Ocean Data Assimilation (SODA) model output (Version 3.4.2) from 1977 to 2016 (dashed line) and Northeast Fisheries Science Center (NEFSC) station data (solid line). Both datasets were sampled and processed using the same methodology. The titles of each subplot show the rho from correlation analyses between the two datasets (dashed and solid lines). 
a) $\mathrm{SS2}$ Winter/Spring $(\mathrm{R}=\mathbf{0 . 8})$

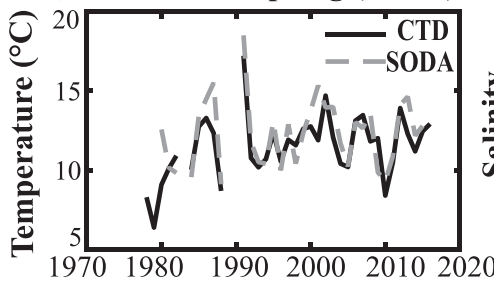

b) $\mathrm{SS} 2$ Summer $(\mathrm{R}=\mathbf{0 . 1 1})$

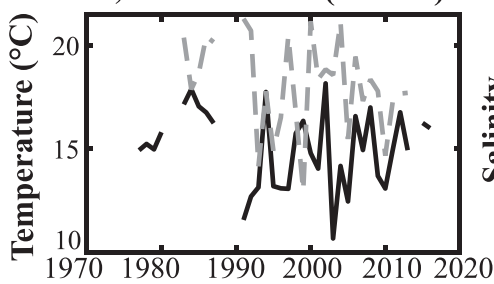

c) $\mathrm{SS} 2 \mathrm{Fall} / \mathrm{Winter}(\mathrm{R}=\mathbf{- 0 . 0 8})$

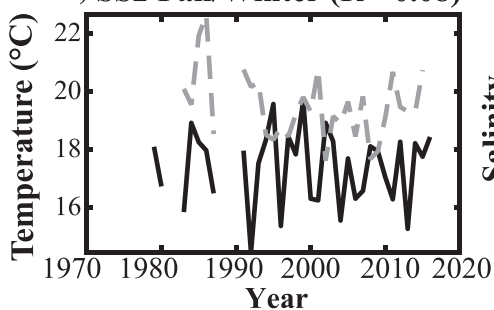

d) $\mathrm{SS2}$ Winter/Spring $(\mathrm{R}=\mathbf{0 . 8})$

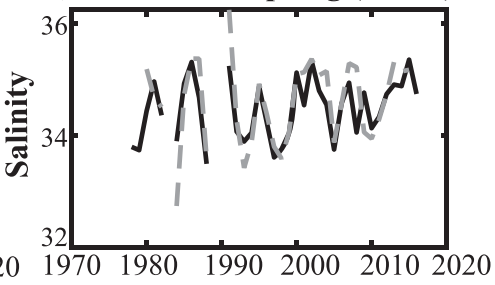

e) $\mathrm{SS2}$ Summer $(\mathrm{R}=\mathbf{0 . 4})$

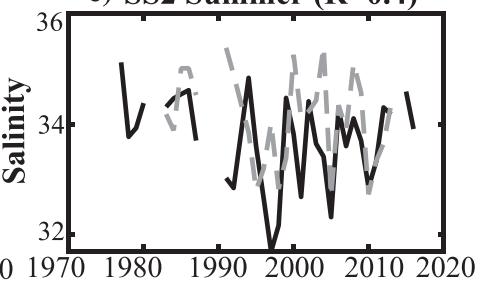

f) $\mathrm{SS} 2$ Fall/Winter $(\mathrm{R}=\mathbf{0 . 3 5})$

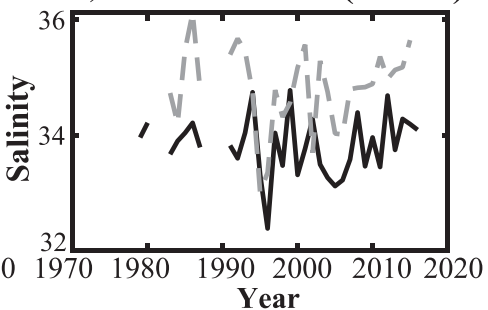

Figure A16. Plots of temperature $(a-c)$ and salinity $(d-f)$ for each season in the Southern Shelf 2 (SS2) region created with Simple Ocean Data Assimilation (SODA) model output (Version 3.4.2) from 1977 to 2016 (dashed line) and Northeast Fisheries Science Center (NEFSC) station data (solid line). Both datasets were sampled and processed using the same methodology. The titles of each subplot show the rho from correlation analyses between the two datasets (dashed and solid lines). 


\section{REFERENCES}

Andres, M. 2016. On the recent destabilization of the Gulf Stream path downstream of Cape Hatteras, Geophys. Res. Lett., 43, 9836-9842. doi: 10.1002/2016GL069966

Appiott, J., M. Balgos, B. Cicin-Sain, K. Hicks, C. Snyder, and N. Targett. 2011. Development of an ocean research plan for the Mid-Atlantic region. A technical report. Sea Grant Mid-Atlantic Ocean Research Planning Project. http://www.midatlanticoceanresearchplan.org/projectapproachandaccomplishments

Beardsley, R. C., and W. C. Boicourt. 1981. On estuarine and continental-shelf circulation in the Middle Atlantic Bight, in Evolution of Physical Oceanography: Scientific Surveys in Honor of Henry Stommel. B. A. Warren and C. Wunsch, eds. Cambridge: MIT Press, 198233. http://ocw.mit.edu/resources/res-12-000-evolution-of-physical-oceanography-spring-2007/ index.htm

Beardsley, R. C., D. C. Chapman, K. H. Brink, S. R. Ramp, and R. Schlitz. 1985. The Nantucket Shoals Flux Experiment (NSFE79). Part I: a basic description of the current and temperature variability. J. Phys. Oceanogr., 15, 713-748. doi: 10.1175/1520-0485(1985)015 $<0713$ :TNSFEP $>2.0$. $\mathrm{CO} ; 2$

Belchansky, G. I., D. C. Douglas, and N. G. Platonov. 2004. Duration of the Arctic sea ice melt season: regional and interannual variability, 1979-2001, J. Clim., 17, 67-80. doi: 10.1175/15200442(2004)017<0067:DOTASI > 2.0.CO;2

Belkin, I. M. 2004. Propagation of the "Great Salinity Anomaly" of the 1990s around the northern North Atlantic, Geophys. Res. Lett., 31, doi: 10.1029/2003GL019334

Belkin, I. M., S. Levitus, J. Antonov, and S. A. Malmberg. 1998. "Great Salinity Anomalies" in the North Atlantic, Prog. Oceanogr., 41, 1-68. doi: 10.1016/S0079-6611(98)00015-9

Bentley, J. L. 1975. Multidimensional binary search trees used for associative searching, Commun. ACM, 18, 509-517. doi: 10.1145/361002.361007

Bigelow, H. B. 1927. Physical oceanography of the Gulf of Maine, Washington: US Government Printing Office.

Bigelow, H. B., and M. Sears. 1935. Studies of the waters of continental shelf, Cape Cod to Chesapeake Bay. II. Salinity, Pap. Phys. Oceanogr. Meteorol., 4, 1-93.

Boon, J. D. 2012. Evidence of sea level acceleration at U. S. and Canadian tide stations, Atlantic Coast, North America, J. Coast. Res., 28, 1437-1446. doi: 10.2112/JCOASTRES-D-1200102.1

Caesar, L., S. Rahmstorf, A. Robinson, G. Feulner, and V. Saba. 2018. Observed fingerprint of a weakening Atlantic Ocean overturning circulation, Nature, 556, 191-196. doi: 10.1038/s41586018-0006-5

Carton, J. A., G. A. Chepurin, and L. Chen. 2018. SODA3: a new ocean climate reanalysis, J. Climate, 31, 6967-6983. doi: 10.1175/JCLI-D-18-0149.1

Chapman, D. C. 1986. A simple model of the formation and maintenance of the shelf/ slope front in the Middle Atlantic Bight, J. Phys. Oceanogr., 16, 1273-1279. doi: 10.1175/ 15200485(1986)016<1273:ASMOTF>2.0.CO;2

Chapman, D. C., J. A. Barth, R. C. Beardsley, and R. G. Fairbanks. 1986. On the continuity of mean flow between the Scotian Shelf and the Middle Atlantic Bight, J. Phys. Oceanogr., 16, 758-772. doi: 10.1175/1520-0485(1986)016<0758:OTCOMF $>2.0 . \mathrm{CO} ; 2$

Chapman, D. C., and R. C. Beardsley. 1989. On the origin of shelf water in the Middle Atlantic Bight, J. Phys. Oceanogr., 19, 384-391. doi: 10.1175/15200485(1989)019<0384:OTOOSW >2.0.CO;2

Choi, B.-J., and J. L. Wilkin. 2007. The effect of wind on the dispersal of the Hudson River Plume, J. Phys. Oceanogr., 37, 1878-1897. doi: 10.1175/JPO3081.1 
Connolly, T. P., and S. J. Lentz. 2014. Interannual variability of wintertime temperature on the inner continental shelf of the Middle Atlantic Bight, J. Geophys. Res. Oceans, 119, 6269-6285. doi: 10.1002/2014JC010153

Drinkwater, K. F. 1996. Atmospheric and oceanic variability in the northwest Atlantic during the 1980s and early 1990s, J. Northwest Atl. Fish. Sci., 18, 77-97. doi: 10.2960/J.v18.a6

Du, J., and J. Shen. 2016. Water residence time in Chesapeake Bay for 1980-2012, J. Mar. Syst., 164, 101-111. doi: 10.1016/j.jmarsys.2016.08.011

Ezer, T., L. P. Atkinson, W. B. Corlett, and J. L. Blanco. 2013. Gulf Stream's induced sea level rise and variability along the U.S. mid-Atlantic coast, J. Geophys. Res. Oceans, 118, 685-697. doi: 10.1002/jgrc.20091

Fairbanks, R. 1982. The origin of continental shelf and slope water in the New York Bight and Gulf of Maine: evidence from H218O/ H216O ratio measurements, J. Geophys. Res., 87, 5796-5808. doi: 10.1029/JC087iC08p05796

Fleming, N. 2016. Seasonal and Spatial Variability in Temperature, Salinity, and Circulation of the Middle Atlantic Bight, Brunswick: Rutgers University, 359 pp.

Fogarty, M., L. Incze, and R. Wahle, D. Mountain, A. Robinson, A. Pershing, et al. 2007. Potential climate change impacts on marine resources of the northeastern United States. https://www. ucsusa.org/sites/default/files/legacy/assets/documents/global_warming/pdf/miti/fogarty_et_al.pdf

Forsyth, J. S. T., M. Andres, and G. G. Gawarkiewicz. 2015. Recent accelerated warming of the continental shelf off New Jersey: observations from the CMV Oleander expendable bathythermograph line, J. Geophys. Res. Oceans, 120, 2370-2384. doi: 10.1002/2014JC010516

Fratantoni, P. S., T. Holzwarth-Davis, C. Bascunan, and M. H. Taylor. 2013. Description of the 2012 Oceanographic Conditions on the Northeast U.S. Continental Shelf, Northeast Fish. Sci. Cent. Ref., Doc. 13-26, 40 pp.

Gawarkiewicz, G. G., R. E. Todd, A. J. Plueddemann, M. Andres, and J. P. Manning. 2012. Direct interaction between the Gulf Stream and the shelfbreak south of New England, Sci. rep., 2, 553. doi: 10.1038/srep00553

Göbel, E., I. M. Mills, and A. Wallard, eds. 2006. The International System of Units (SI), Paris: Bureau International des Poids et Mesures, $127 \mathrm{p}$.

Gong, D., J. T. Kohut, and S. M. Glenn. 2010. Seasonal climatology of wind-driven circulation on the New Jersey Shelf, J. Geophys. Res. Oceans, 115, C04006. doi: 10.1029/2009JC005520

Korhonen, M., B. Rudels, M. Marnela, A. Wisotzki, and J. Zhao. 2013. Time and space variability of freshwater content, heat content and seasonal ice melt in the Arctic Ocean from 1991 to 2011, Ocean Sci., 9, 1015-1055. doi: 10.5194/os-9-1015-2013

Lentz, S. J. 2003. A climatology of salty intrusions over the continental shelf from Georges Bank to Cape Hatteras, J. Geophys. Res., 108, 1-12. doi: 10.1029/2003JC001859

Lentz, S. J. 2008. Observations and a model of the mean circulation over the Middle Atlantic Bight continental shelf, J. Phys. Oceanogr., 38, 1203-1221. doi: 10.1175/2007JPO3768.1

Lentz, S. J. 2010. The mean along-isobath heat and salt balances over the Middle Atlantic Bight continental shelf, J. Phys. Oceanogr., 40, 934-948. doi: 10.1175/2009JPO4214.1

Linder, C. A., and G. Gawarkiewicz. 1998. A climatology of the shelfbreak front in the Middle Atlantic Bight, J. Geophys. Res., 103, 18 405-18 423.

Manning, J. 1991. Middle Atlantic Bight salinity: interannual variability, Cont. Shelf Res., 11, 123137. doi: 10.1016/0278-4343(91)90058-E

Markus, T., J. C. Stroeve, and J. Miller. 2009. Recent changes in Arctic sea ice melt onset, freezeup, and melt season length, J. Geophys. Res. Oceans, 114, C12024. doi: 10.1029/2009JC005436 
Meise-Munns, C., J. Green, M. Ingham, and D. G. Mountain. 1990. Interannual variability in the copepod populations of Georges Bank and the western Gulf of Maine, Mar. Ecol. Prog. Ser., 65, 225-232. doi: 10.3354/meps065225

Mills, K. E., A. Pershing, and C. Brown, Y. Chen, F.-S. Chiang, D. S. Holland, et al. 2013. Fisheries management in a changing climate: lessons from the 2012 ocean heat wave in the Northwest Atlantic, Oceanography, 26, 191-195. doi: 10.5670/oceanog.2013.27

Mountain, D. G. 1991. The volume of shelf water in the Middle Atlantic Bight: seasonal and interannual variability, 1977-1987, Cont. Shelf Res., 11, 251-267. doi: 10.1016/0278-4343(91)90068-H

Mountain, D. G. 2003. Variability in the properties of shelf water in the Middle Atlantic Bight, 1977-1999, J. Geophys. Res., 108, 1-11. doi: 10.1029/2001JC001044

Mountain, D. G., and J. P. Manning. 1994. Seasonal and interannual variability in the properties of the surface waters of the Gulf of Maine, Cont. Shelf Res., 14, 1555-1581. doi: 10.1016/02784343(94)90090-6

Mountain, D. G., and M. H. Taylor. 1998. Spatial coherence of interannual variability in water properties on the U.S. northeast shelf, J. Geophys. Res. Oceans., 103, 3083-3092.

Pickart, R. S. 2000. Bottom boundary layer structure and detachment in the shelfbreak jet of the Middle Atlantic Bight*, J. Phys. Oceanogr., 30, 2668-2686. doi: 10.1175/1520-0485(2001)031 $<2668$ :BBLSAD $>2.0 . \mathrm{CO} ; 2$

Schofield, O., R. Chant, B. Cahill, R. Castelao, D. Gong, A. Kahl, et al. 2008. The decadal view of the Mid-Atlantic Bight from the COOLroom: is our coastal system changing? Oceanography, 21, 108-117. doi: 10.5670/oceanog.2008.08

Schubel, J., and D. Pritchard. 1987. A brief physical description of the Chesapeake Bay, in Contaminant Problems and Management of Living Chesapeake Bay Resources. S. K. Majumdar, L. W. Hall, and H. M. Adams, eds. Philidelphia: The Pennsylvania Academy of Science, 1-32.

Shearman, R. K., and S. J. Lentz. 2010. Long-term sea surface temperature variability along the US East Coast, J. Phys. Oceanogr., 40, 1004-1017. doi: 10.1175/2009jpo4300.1

Shepard, D. 1968. A two-dimensional interpolation function for irregularly-spaced data, in Proceedings of the 1968 23rd ACM national conference, New York, NY, August 27-29, 1968, 517-524. doi: $10.1145 / 800186.810616$

Sherman, K. 1980. MARMAP, a fisheries ecosystem study in the Northwest Atlantic: fluctuations in ichthyoplankton-zooplankton components and their potential for impact on the system, in Advanced concepts on ocean measurements for marine biology. F. P. Diermer, F. J. Vernberg, and D. Z. Mirkes, eds. Columbia: University of South Carolina Press, 9-37.

Smith, P. 1983. The mean and seasonal circulation off southwest Nova Scotia, J. Phys. Oceanogr., 13, 1034-1054. doi: 10.1175/15200485(1983)013 <1034:TMASCO > 2.0.CO;2

Smith, P. C., R. W. Houghton, R. G. Fairbanks, and D. G. Mountain. 2001. Interannual variability of boundary fluxes and water mass properties in the Gulf of Maine and on Georges Bank: 1993-1997, Deep Sea Res. Part 2 Top. Stud. Oceanogr., 48, 37-70. doi: 10.1016/S0967-0645(00)00081-3

Thompson, C. 2010. The Gulf of Maine in Context. State of the Gulf of Maine Report, Dartmouth: Gulf of Maine Council on the Marine Environment.

Thomson, R. E., and W. J. Emery. 2014. Data Analysis Methods in Physical Oceanography, 3rd ed, Amsterdam: Elsevier Science.

Thornalley, D. J. R., D. W. Oppo, P. Ortega, J. I. Robson, C. M. Brierley, R. Davis, et al. 2018. Anomalously weak Labrador Sea convection and Atlantic overturning during the past 150 years, Nature, 556, 227-230. doi: 10.1038/s41586-018-0007-4

Voorhis, A. D., D. C. Webb, and R. C. Millard. 1976. Current structure and mixing in the shelf/slope water front south of New England, J. Geophys. Res., 81, 3695-3708. 
Walsh, J. J., P. E. Biscaye, and G. T. Csanady. 1988. The 1983-1984 shelf edge exchange processes (SEEP)-I experiment: hypotheses and highlights, Cont. Shelf Res., 8, 435-456. doi: 10.1016/02784343(88)90063-5

Weatherall, P., K. M. Marks, M. Jakobsson, T. Schmitt, S. Tani, J. E. Arndt, et al. 2015. A new digital bathymetric model of the world's oceans, Earth Space Sci., 2, 331-345. doi: 10.1002/2015EA000107

Received: 20 June 2017; revised: 15 February 2019. 